


\section{Talent Match Evaluation: Involving Young People}

Authors

Nadia Bashir

Sarah Pearson

Elizabeth Sanderson

Peter Wells

For further details contact: Professor Peter Wells (Evaluation Director) at p.wells@shu.ac.uk / 01142253073

October 2018

DOI: 10.7190/cresr.2018.3465668226 


\section{Acknowledgements}

We are extremely grateful to all those who have helped in the course of the evaluation. We are particularly grateful to the staff, young people and board members of the 21 Talent Match partnerships who have given their time freely to support the evaluation. A particular mention should be made of partnership leads and those involved in setting up the Common Data Framework (CDF). We trust that in time the considerable benefits of the CDF will be seen in terms of contributing to a robust evidence base on which to design future policies and programmes.

A wide range of staff and committee members at the Big Lottery Fund have helped, supported and advised upon the evaluation. Their time has been invaluable. We are particularly grateful to Jolanta Astle, Sarah Cheshire, James Godsal, Scott Hignett, Scott Highland, Matt Poole and Roger Winhall. We are also grateful to former Big Lottery Fund colleagues Linzi Cooke and Scott Greenhalgh who provided invaluable assistance at the start of the Talent Match Evaluation.

Lastly, we would like to thank the evaluation team at Sheffield Hallam University, the University of Birmingham, the University of Warwick and Cambridge Economic Associates: Duncan Adam, Gaby Atfield, Dr Sally-Anne Barnes, Nadia Bashir, Dr Richard Crisp, Dr Chris Damm, Dr Maria de Hoyos, Dr Will Eadson, Professor Del Roy Fletcher, Dr Tony Gore, Professor Anne Green, David Leather, Elizabeth Sanderson, Emma Smith, Louise South, Professor Pete Tyler, Sarah Ward and lan Wilson. We would also like to thank our former colleague Ryan Powell who supported the original evaluation design.

Peter Wells (Evaluation Director) and Sarah Pearson (Evaluation Project Manager) 


\section{Contents}

Summary i

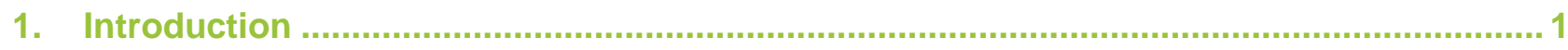

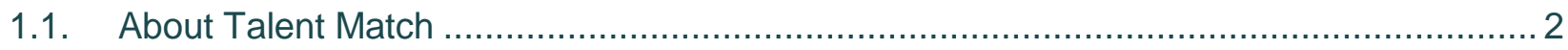

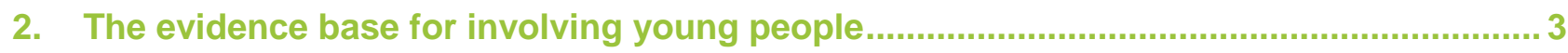

3. Involving young people in Talent Match ......................................................... 5

4. Who has been involved?

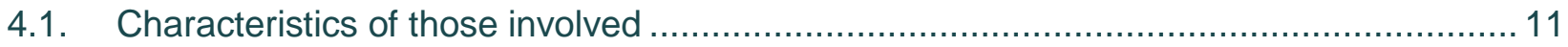

4.2. Support received from Talent Match partnerships............................................ 16

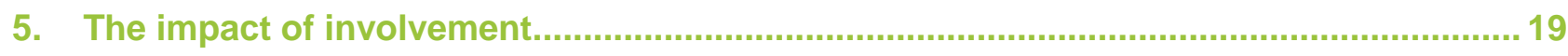

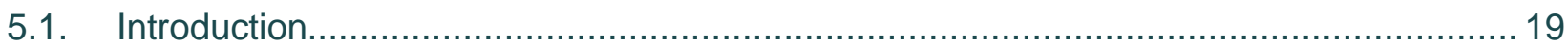

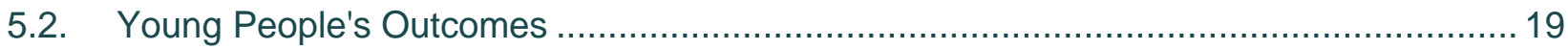

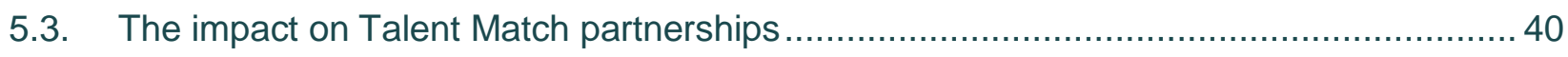

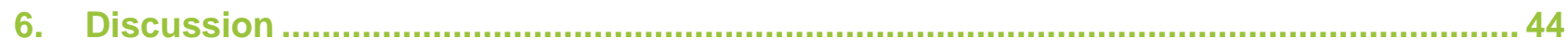

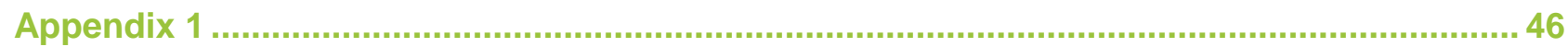




\section{Summary}

This report draws together evidence on the involvement of young people in Talent Match, gathered through the evaluation of the programme between 2013 and 2018. It is intended for audiences interested in both the process and impact of involving young people in public services.

The report explores:

- How have Talent Match partnerships involved young people?

- Which groups of young people have been involved in Talent Match?

- What difference does involvement make to young people and Talent Match partnerships?

All Talent Match beneficiaries have co-produced their own employment journeys through close engagement with key workers. This report is concerned specifically with those young people who have been 'formally' involved in the design, delivery and evaluation of Talent Match through participation in processes and forums which aim to inform, influence or lead various aspects of the programme.

\section{About Talent Match}

Talent Match is a £106 million innovative programme funded by the Big Lottery Fund to address unemployment amongst 18-24 year olds. It is being delivered using National Lottery funding between 2014 and 2018 through partnerships in 21 Local Enterprise Partnership areas in England. The programme seeks to support young people who are furthest from the labour market through personalised, non-standardised provision which addresses their needs and aspirations. Participation in the programme is voluntary, and a key innovation of Talent Match is that it has been co-designed by and is co-delivered with young people. This sets it apart from previous youth employment initiatives and current government employment programmes.

The Talent Match programme is being evaluated by a consortium of partners led by the Centre for Regional Economic and Social Research (CRESR) at Sheffield Hallam University working with the Warwick Institute for Employment Research at the University of Warwick, City-REDI at the University of Birmingham and Cambridge Economic Associates. The evaluation runs from 2013 until 2019.

\section{Involving young people in Talent Match}

Seven per cent of Talent Match beneficiaries had been actively involved in the design or delivery of local programmes by the end of 2017. This represents 1,498 young people. This means that in each Talent Match partnership an average of 71 young people have engaged in processes which have influenced employment support for young people in their area. This is a significant step-change in the delivery of services designed to meet the needs of this group. 
There has been a wide variety of approaches to involvement, many of which have been genuinely innovative. Four approaches can be identified, which are common across many Talent Match partnerships:

- Youth-led governance and consultation groups which have a representative function on or influence on wider governance structures such as partnership boards, steering groups and commissioning panels.

- Individuals or groups of young people with a remit to engage young people in Talent Match and deliver peer support and training - often termed as Talent Match 'Champions' or 'Ambassadors'.

- Groups which have a remit to help develop and/or deliver services which respond to the needs of young people, either through advising service development or direct delivery.

- Influencing policy and practice locally, giving feedback to employers, local authorities and Jobcentre Plus.

\section{Who has been involved?}

The majority of young people who have been involved are male, and aged over 21 years. Compared to those who have not been more involved they are older, more likely to have a limiting or non-limiting disability, and be non-heterosexual. They are also more likely to be better qualified, have completed an apprenticeship or formal education before joining Talent Match, or to have undertaken a work placement or volunteering (although less likely to have been in paid employment or to have experienced negative prior life experiences), and they have received more support from Talent Match. All of these differences are statistically significant.

\section{The Impact of involvement}

Young people who have been involved in Talent Match experience greater improvements in confidence, setting and achieving goals, communication, managing feelings, working with others and reliability compared to their peers who have not been involved. They are also more likely to enter education, an apprenticeship or placement, or take up volunteering. This suggests that involvement in the governance and delivery of the programme has provided these participants with an opportunity to develop valuable skills, and a route to participation in training and volunteering.

The evaluation found no clear relationship between involvement and employment or overall well-being outcomes for Talent Match participants. This is perhaps a reflection of the importance of involvement as a mechanism for supporting young people who are facing some of the biggest challenges to taking up work.

Case studies confirm that those who embed in the Talent Match structures report an increase in confidence, an improvement in social skills, and a sense of worth. Talent Match acts as a protective scaffold where, for example, family fail to provide this. In cases where young people have a sense of security and access to support, they fair well even if confidence and sense of worth is low. Encouragement and guidance, whether that is from Talent Match or family, impacts on individuals' outcomes positively. However, some needs are so complex, for example, based on learning difficulties or chaotic lives, that the support has a lesser or short-lived impact.

For partnerships, young people's involvement has been overwhelmingly positive, and has assisted delivery across all elements of the programme. Young people's involvement ensures that the voice of young people has helped to shape the nature of Talent Match activities and those of local partners, including employers. 


\section{Daniel}

When Daniel first engaged with Talent Match he was struggling with communication, finding it very difficult to work with others, and had problems with his mental health. Daniel became involved in the local Talent Match steering group. He began to meet people and get out and about, and with this, his confidence began to grow. He commented:

I'm not very comfortable around new people at the start and I can be really awkward. As I grew to know these people [in the steering group] I grew a bit more open with the way I talk to people. I needed a way to get to know new people and understand and bring my communication skills back up because at first it was a bit slow cos it was formal and I was a bit intimidated but I was sitting around with people and eventually I got my confidence up and I could talk freely with them which I'm really happy for.

He also took up other opportunities, including attending a skills show and sitting on a recruitment panel: "It was a massive confidence boost, I honestly loved it...it's surprisingly enjoyable". Daniel recognised that by meeting people, and participating in activities, such as a residential, and visiting other Talent Match partnerships, he was able to develop his social skills.

Daniel has secured employment through Talent Match and although he is still experiencing mental health issues, he feels that involvement in Talent Match had been an important contributing factor in finding work. He commented:

If it wasn't for being in social situations I would have found it really awkward to go and talk to people so that would have affected me being able to go to work.

\section{Talent Match London}

Talent Match London has engaged young people in peer mentoring and active leadership roles. One delivery partner in East London described how Talent Match had "devolved more power to their youth board" by engaging young people proactively in developing employer links and networks. This was described as: "been fantastic - it's boosted numbers and provision". Social and networking facilities for young people were provided through a 'youth room': a space available every Friday afternoon for young people to meet and play games (pool, table tennis etc.) whilst "meeting like-minded people who are moving forward and not held back by their peers". Employers and service providers also attend to meet young people and provide training and information.

Interviewees highlighted benefits to involving young people:

- Potential beneficiaries are more likely to sign up if they know that the programme has been designed by young people. One Youth Board member in East London attributed the rise in numbers (from four to 14) to the perception that 'someone was voicing the opinion of young people'.

- More effective outreach activities as young people know best how to do this.

- Better engagement of employers as they know that the programme is youth-led which enhances the commitment of young people.

- Facilitating partnership between delivery organisations: 'It's not about competition all the time' [Youth Board member].

- Encouraging innovation and effective delivery among partners as a result of young people's evaluation. One example is a delivery partner that had restructured staffing arrangements in response to feedback from young people.

- Improving the skills and confidence of young people. One Youth Board member described it as a 'great experience'. 
Lessons from the evidence on young people's involvement in Talent Match include:

1. Young people's involvement has many forms and changes over time. The ambition to place young people at the centre of Talent Match has been realised by providing a wide range of opportunities for involvement, building in opportunities for social activity and peer support, and learning from experience and revising approaches over time. The ability of Talent Match partnerships to respond flexibly to the views and priorities of young people has been important in encouraging, and sustaining, young people's involvement.

2. Young people's involvement improves service quality. Some of the key impacts of young people's involvement are in influencing the work of Talent Match partnerships and other stakeholders, which include employers. This has ensured that the voice of young people has informed the development and delivery of provision across Talent Match areas, and has enhanced the experience of and impact of employment support for all Talent Match beneficiaries. There would be clear benefits to embedding young people's involvement into future provision to ensure that it meets the needs of young people.

3. Involvement is an important mechanism for supporting young people who are facing some of the most challenging barriers to labour market participation. The young people involved in Talent Match have included those with disabilities and mental health issues. Opportunities for involvement have enabled these young people to develop skills that they might not otherwise have obtained.

4. Involvement helps young people to move closer to the labour market. Those young people who have been involved in Talent Match are more likely to enter formal education, secure an apprenticeship or work placement or take up volunteering than those who have not been involved. These are important steps toward sustained employment, particularly for young people who don't have experience of paid work.

5. Involvement supports young people to build skills and confidence. Young people who have been involved in Talent Match report greater gains particularly in confidence, communication skills, goal setting managing feelings, working with others and reliability. In future employability programmes there may be a rationale in seeking to support involvement of those groups for whom these attributes and skills are particularly low.

6. Involvement one is part of a range of support that is needed to help young people to progress. The fact that there has been no direct relationship between involvement and improved employment outcomes for young people involved in Talent Match is a reflection of the challenges that this group are facing in finding work. Involvement should be seen as a complement to, but not a replacement for, a range of other activities to support young people to overcome barriers to labour market participation. 


\section{Introduction}

This report draws together evidence on the involvement of young people in the activities of Talent Match partnerships. It reviews the nature and extent of young people's involvement in the design and delivery of Talent Match, and discusses the impact of this on outcomes for young people and Talent Match partnerships. It then goes on to discuss the implications for the involvement of young people in the design and delivery of employment support. It is intended for audiences interested in both the process and impact of involving young people in public services.

The report addresses two questions:

- Which groups of young people have been involved in Talent Match?

- What difference does involvement make to young people and Talent Match partnerships?

It draws on a range of data sources:

- An annual programme of visits to Talent Match partnerships carried out between 2014 and 2016 and involving face-to-face interviews with partnership leads, strategic partners, and delivery partners.

- Surveys of lead partner organisations and delivery organisations conducted in 2014, 2015 and 2018.

- Data on the characteristics, progress and outcomes of programme beneficiaries collected through a through a Common Data Framework.

- Interviews with young people participating in the Talent Match programme: semi-structured interviews with Talent Match beneficiaries were conducted in two waves between 2015 and 2017. A total of 61 interviews were carried out in wave 1 , and 66 interviews in wave 2 . Fifty seven percent of interviewees who participated at wave 1 were also interviewed at wave $2(n=35)$.

- Case studies of four young people participating in Talent Match. ${ }^{1}$

- An evidence review of the involvement of young people. ${ }^{2}$

\footnotetext{
${ }^{1}$ The four case studies have been developed using the following evidence: multiple Common Data Framework survey responses for each young person; in-depth qualitative interviews that were conducted as part of longitudinal research (in 2015 and 2016) with two of the young people; recent (2018) in-depth qualitative interviews conducted with all four young people. Pseudonyms have been used to protect the identity of the young people.

2 Bashir, N. et al (2014) Involvement of Young People: an evidence review. Talent Match Evaluation and Learning Contract: 2013-19. Sheffield Hallam University, University of Warwick, Big Lottery Fund.
} 
- A thematic case study of the involvement of young people in Talent Match. ${ }^{3}$

- Engagement with Talent Match partnerships through events and workshops which have explored a range of aspects of Talent Match provision.

\subsection{About Talent Match}

The Big Lottery Fund has invested $£ 106$ million in Talent Match, an innovative programme designed to address unemployment amongst 18-24 year olds. It is being delivered between 2014 and 2018 through partnerships in 21 Local Enterprise Partnership areas in England. The programme seeks to support young people who are furthest from the labour market through personalised, non-standardised provision which addresses their needs and aspirations.

Participation in the programme is voluntary, and a key innovation of Talent Match is that it has been co-designed by and is co-delivered with young people. This sets it apart from previous youth employment initiatives and current government employment programmes.

The Talent Match programme is being evaluated by a consortium of partners led by the Centre for Regional Economic and Social Research (CRESR) at Sheffield Hallam University working with the Warwick Institute for Employment Research at the University of Warwick, City-REDI at the University of Birmingham and Cambridge Economic Associates. The evaluation runs from 2013 until 2019.

\footnotetext{
${ }^{3}$ Atfield, G. et al (2014), A challenge to the status quo: early experiences of involving young people in the Talent Match programme, Talent Match Case Study Theme Report. Sheffield Hallam University, University of Warwick, Big Lottery Fund.
} 


\section{The evidence base for involving young people}

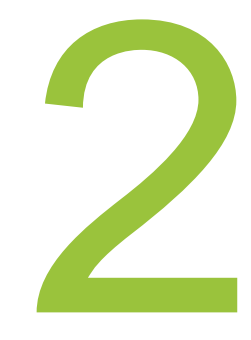

There is an extensive evidence base on the rationale for, process and impact of the involvement of service users in the design and delivery of public services, which has been developed over several decades, particularly but not solely in the fields of health and social care. Service user involvement is anticipated to bring a range of benefits, which may include increased voice for those affected by policy interventions, improvements to service effectiveness through increased levels of engagement and improved outcomes, and greater efficiency as a result of reductions in levels of spend on services which users do not need or use. In addition, there may be benefits for the individuals involved, by way of skills development, improved confidence and enhanced networks.

Accordingly, there is extensive guidance on involving young people in decision making, although less evidence relates to the involvement of young people, and even less to the involvement of those who are not in employment, education or training (NEET). Similarly, much evidence relates either to the involvement of children and young people under the age of 18 years. There has been, hitherto, very little evidence which explores the possibilities, limitations and benefits of involving young adults aged 18 to 24 years in the design and delivery of employment support.

In view of this, a review of the evidence base for the involvement of young people was undertaken by the evaluation team at the outset of the Talent Match evaluation in 2014. It looked at the evidence for the involvement of young people in partnerships and research, and highlighted a number of findings:

1. Literature on the involvement of 18-24 year old NEETS in the design and delivery of programmes is sparse. What lessons are drawn are often inferred from literature on the involvement of other population groups (such as under 18s or excluded groups) or from involvement in community development.

2. The rationale for involvement of young people in policy making and delivery includes factors including the need for policy to be informed by real world lived experiences, the scope for the status quo to be challenged by fresh insights, and for solutions to be shaped by experience.

3. Involvement of young people in service design can be seen to bring three broad benefits: practical benefits for service design, to support a broader ideal of citizenship and social inclusion, and personal and social benefits for those directly participating.

4. It is helpful for involving organisations to be very clear as to what they mean by involvement. Whilst this may be seen as a ladder of involvement (from consultation up to ownership), it is perhaps better to think of three broad approaches: consultation; co-production of services; and ownership. 
5. The barriers to involvement of different service user groups provide useful lessons for partnerships to take stock of what is being addressed and can such barriers be overcome. Such barriers include: strategic and leadership barriers (e.g. involvement is not championed as being part of all an organisation's activities, or insufficient resources are provided to involve); organisational barriers (e.g. staff lack the requisite skills and it's not clear whose responsibility involvement is) and barriers faced by young people themselves (e.g. their own related and unrelated needs, the risks of involving the easier to involve); and approaches to involvement (e.g. making assumptions about how engagement should work from the outset).

6. Approaches to overcoming barriers to involvement often combine the following: positive and clear communication; resources, energy and time; realism; sustainability of approaches over time; maintaining a clear sight of goals.

7. Evidence of the benefits of involvement of 18-24 young people in research and evaluation activities is limited. Nonetheless there are examples of good practice and guidance of where and how to start.

8. Benefits from the involvement of young people in research lie in two main areas: for organisations gaining new insights into problems; and for young people themselves from the new skills and experience they may gain.

9. Potential problems with the involvement of young people in research and evaluation lie in a number of areas: the required skills in organisations to manage young people researchers; the need to establish new procedures for ethics and health and safety; ensuring that involvement is not tokenistic and add new insights.

10. Talent Match provides an opportunity to generate new insights into the involvement of young people; this recognises that existing literature is limited. Relevant areas to consider focus in particular on understanding which practices of involvement appear to have been most successful and what are the reasons for their success.

The final finding highlights the potential for the evaluation of the Talent Match programme to produce new evidence on the process and impact of involving young people, particularly in the absence of a wider literature. This report contributes to that evidence by pulling together evidence on the approaches that partnerships have taken to engagement, looking at the extent of involvement and the characteristics of young people who have been involved, and exploring relationships between involvement and outcomes for Talent Match beneficiaries.

This section has provided a brief review of the evidence for involving young people. The next section looks at approaches to involving young people in Talent Match. 


\section{Involving young people in Talent Match}

As outlined in the introduction to this report, the involvement of young people in the co-design and co-production of services is perhaps the key defining feature of Talent Match and one that differentiates it significantly from mainstream employment services. Placing young people at the heart of the programme, and a belief in the abilities of young people to improve their own circumstances and life chances through targeted and personalised support, has been central to an approach in which Talent Match partnerships have sought to provide individualised solutions based on the needs and aspirations of young people. All Talent Match beneficiaries have, to a greater or lesser extent, co-produced their own employment journeys through close engagement with key workers ${ }^{4}$ and participation in holistic, intensive services. This report is, concerned specifically with the experiences of those young people who have been 'formally' involved in the design and delivery of Talent Match through participation in processes and forums which aim to inform, influence or lead the activities of Talent Match partnerships. For the purposes of this report we have identified a range of activities in which young people have been involved:

- evaluation, research and gathering feedback;

- engaging other young people/ outreach;

- marketing;

- membership of a core partnership group or committee;

- media and dissemination;

- delivering services;

- management of Talent Match partnership and/or service delivery;

- commissioning of services;

- other.

Data provided by the Talent Match partnerships and collected through the 2018 partnership survey provides evidence on the extent and scope of young people's involvement. ${ }^{5}$

\footnotetext{
${ }^{4}$ Barnes et al (2017) Key worker models: what key worker approaches, capacities and capabilities are important at different stages of the journey to employment? Sheffield Hallam University/ University of Warwick/ Big Lottery Fund.

${ }^{5}$ Partnerships were asked to specify which young people engaged by the end of December 2017 had been actively involved in the programme and which had not. If they were not sure if a young person had been actively involved they were asked to indicate this. These cases where their status was unknown have been excluded from the analysis presented.
} 
Seven per cent of young people participating in Talent Match by the end of 2017 had been actively involved. This represents 1,498 young people and means that in each Talent Match partnership an average of 71 young people has been involved in the design and/or delivery of local services. They have been particularly involved in peer activities, research and evaluation. A range of approaches have been taken, which have developed over time in response to the needs and priorities of young people.

The most common way these young people had been involved was through evaluation, research and gathering feedback which is likely to have influenced the design and delivery of Talent Match approaches. Over half were involved this way. Almost half were also involved in engaging other young people or outreach activities. Fewer were involved in other ways; notably less than one fifth had been involved in commissioning services (Figure 3.1).

Figure 3.1: Types of youth involvement

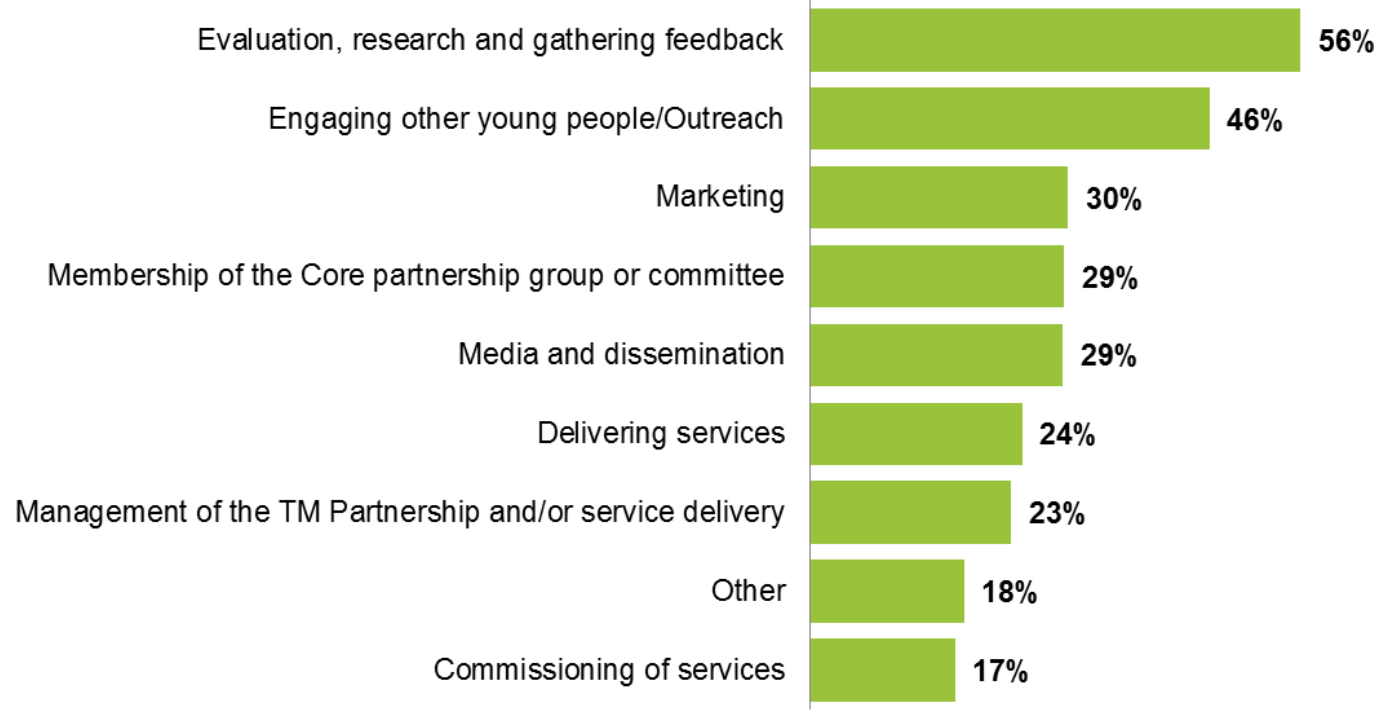

Base: 1,498

Source: 2018 survey of Talent Match partnerships

Inevitably, across the 21 Talent Match partnerships there has been a wide variety of approaches to involvement, many of which have been genuinely innovative. It is not possible in this report to explore all of the mechanisms for engagement, although some examples are highlighted throughout this report. In addition, case study research ${ }^{6}$ carried out at the outset of the programme, and ongoing discussion with partnerships has highlighted four mechanisms, which are common across many Talent Match partnerships:

- Youth-led governance and consultation groups which have a representative function or influence on wider governance structures such as partnership boards, steering groups and commissioning panels: examples include the Youth Panel in Greater Manchester, the Youth Boards in London and Generation E in Cornwall.

\footnotetext{
${ }^{6}$ Atfield, G. et al (2014) A challenge to the status quo: early experiences of involving young people in the Talent Match programme, Talent Match Case Study Theme Report. Sheffield Hallam University, University of Warwick, Big Lottery Fund.
} 
- Individuals or groups of young people with a remit to engage young people in Talent Match and deliver peer support and training - often termed as Talent Match 'Champions' and 'Ambassadors': examples include Champions employed as peer mentors in Northamptonshire, youth leaders in Talent Match North East who have co-designed promotional materials and engaged peers through face to face events and social media, and Talent Match Leeds' Young Ambassadors who co-deliver induction days for all young people who join the programme locally.

- Groups which have a remit to help develop and/or deliver services which respond to the needs of young people, either through advising service development or direct delivery: for instance, the six Talent Match Apprentices in Cornwall who each lead on different aspects of delivery depending on their skills and experience, and the Northants Talent Match Challenge Group which each year identifies an event or project to run and is given a budget by the Talent Match partnership.

- Influencing policy and practice locally, giving feedback to employers, local authorities and Jobcentre Plus: for example Generation E in Cornwall has advised a local employer on employment issues.

In reality, there is a high level of cross over between these functions, and involved young people are likely to be involved in a range of activities.

\section{Talent Match Greater Lincolnshire}

In Greater Lincolnshire, the impetus to develop young people as Area Ambassadors came from the 'Talent Match Rocks' event - where some of the advantages of "young people communicating and engaging with young people" became apparent' (interviewee). Each Area Ambassador role is full-time. The Area Ambassadors meet physically and keep in touch electronically and by conference call - and so can work as a team. The Area Ambassadors have been involved in compiling an 'asset map' of facilities in their local area, undertaken evaluation training, buddying and shadowing of Youth Advocates (i.e. the individuals providing ongoing personalized support to Talent Match beneficiaries), and have delivered 'Getting to Know Me' events to encourage young people in their local area to come together. Interviewees were very positive about the introduction of Area Ambassadors and their support in trying to involve other young people in Talent Match. Importantly, the Area Ambassadors are core partnership members - and comments includes "now the voice of young people is starting to come through", whereas previously "it was being translated" by intermediaries. The Area Ambassadors are the "voice of the young people".

In partnership visits, interviewees reflected that approaches to involving young people had developed over time, as learning has been gathered around where young people can best contribute. In some areas, previously open approaches to the involvement of a range of young people had been narrowed to focus on providing intensive support for the meaningful involvement of Talent Match beneficiaries (particularly those facing barriers and challenges). In others, structures and forums for participation increased in size, with a view to embedding youth involvement activities firmly into partnership work. The capacity for reflection, and change, is an important learning point as in all Talent Match partnerships, the needs and purposes of youth involvement have evolved over time. 


\section{Talent Match D2N2}

The ambition for young people's participation in Talent Match D2N2 is "to shape policy for the future". The approach has developed over time, with recognition that there was a need for a range of different opportunities for participation. A 'menu' of participation opportunities has included involvement in commissioning processes, attendance at the Programme Board, and engagement in Youth Forums which support local decision making around project delivery. Young people are supported in these roles by a Young People's Participation Officer. Social activities have also been offered, to encourage a wide range of young people to engage.

Involving young people in decision-making has proved challenging for many partnerships, and alongside organisational learning there has been recognition that young people themselves need support and development to enable them to engage. One interviewee, for example, suggested that young people's involvement was limited by their lack of confidence and experience and that participation should be limited to those with employment experience. This was a lone view however, although all partnerships endeavoured to help young people to develop confidence and skills to ensure that their involvement was both meaningful, and enjoyable. Where this has been successful, benefits to co-production have included influencing the development of services which are genuinely responsive to young people's needs, which in some cases has revealed issues which had not previously been considered.

\section{Talent Match Humber}

In Talent Match Humber, the Young People's Partnership was restructured, as in the early days of the programme it had been open to non-beneficiaries. An open approach had led to the activities of the Young People's Partnership not being entirely relevant to Talent Match beneficiaries and a high turnover of attendees, as non-beneficiaries tended to move on quickly.

Emerging out of the restructuring was the People Against Disability Discrimination (PADD) group. The PADD group was established as a response to the particular needs and issues faced by young people with disabilities to promote awareness of these issues and make people aware of the benefits of employing young people with disabilities.

The group has proved very successful and the young people involved are very engaged and committed to the group. Many of the group had experienced challenges in finding work, and the PADD group provided an important way to reengage these young people. The facilitation and development of the PADD group had also involved some positive learning for Talent Match staff. Key learning points included:

- The need to test the understanding of PADD group members by asking them to reflect and recount.

- The need to simplify language and processes.

- The importance of an acknowledgement and understanding of the complexities of everyday life for many group members.

- The realisation of learning difficulties as a key milestone for some group members.

- That realisation, engagement and involvement can sometimes lead to frustration and anger. 
This section has provided evidence on the ways in which young people have been involved in the Talent Match programme. It has confirmed that although a relatively small proportion of the total number of Talent Match participants has been formally involved in the design and delivery of the programme, those young people who have been involved have engaged in a range of ways across all aspects of the provision. Perhaps as would be expected, young people have been most involved in peer activities: research and evaluation, and outreach. There has been less involvement in the 'managerial' aspects of the programme: day to day management of the partnership and service delivery, and commissioning of services, although in some cases young people have been involved in these aspects, perhaps in advisory or apprentice roles. The next section looks at the scope of young people's involvement and the characteristics of the young people who have been involved in the co-design and co-delivery of Talent Match. 


\section{Who has been involved?}

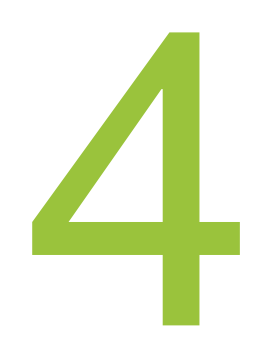

This section provides an overview of the characteristics of the young people more actively involved in the design and delivery of the Talent Match programme.

This section (and the next Section, 5) looks at self-reported measures collected through a Common Data Framework (CDF) which all young people engaged on Talent Match are expected to complete, and data collected by partnerships detailing which young people have been actively involved in the programme and how.

The CDF has been designed in the form of an online questionnaire. Data are collected at a baseline stage (on entry to the programme) and then at three, six, 12, 18 and 24 months. The aim of this is to understand progress into employment but also to pick up issues of labour market progress, other factors (such as health, family circumstance or housing) and ultimately whether the labour market experience is 'fulfilling'. The analysis presented is based on CDF data collected up until the end of March 2018. ${ }^{7}$

The data collected by partnerships focuses on young people engaged by the programme up to the end of December 2017. Partnerships were provided with lists of young people engaged by this point and recorded on the CDF and asked to identify which young people had been actively involved and in what ways. One partnership was unable to provide any information, so beneficiaries from this partnership do not feature in the analysis presented here. There were also five partnerships that indicated only where young people had been most heavily involved, for example through membership of a youth panel or as a 'youth ambassador's. In addition, two partnerships provided information on a section of young people involved rather than every young person listed. Where no information was provided, cases have been excluded from the analysis.

The data collated by partnerships has been linked to the CDF responses in order to examine the characteristics of these young people and the outcomes they have achieved. It is important to note that the data collected by partnerships is not able to show when young people were involved and for how long.

\footnotetext{
${ }^{7}$ Responses to the 24 month survey have not been included in the analysis as a relatively low number of responses had been received by the end of March 2018.

${ }^{8}$ For the purposes of analysis those not indicated as being heavily involved have presumed to have not been involved at all. The descriptive analysis was also run with these cases excluded for reference and the results were similar.
} 


\subsection{Characteristics of those involved}

This section provides detail on the characteristics of the young people who have been involved in the activities of Talent Match partnerships compared to those who have not been as involved. A z-test for proportions has been used to test for statistical differences between the two groups ${ }^{9}$.

Young people involved in Talent Match are more likely to be male, aged over 21 years, to have a disability and to report their sexuality as other than heterosexual, when compared to those who have not been involved. They are less likely to have children.

\section{Protected characteristics/equalities}

Figures 4.1 to 4.7 provide a brief overview of the personal characteristics of the two groups. A slightly larger proportion of those actively involved were male compared to those not involved while a noticeably larger proportion of those actively involved indicated a limiting or non-limiting disability compared to those not involved (35 per cent in comparison to 23 per cent). These differences were identified as statistically significant.

Figure 4.1: Gender by involvement
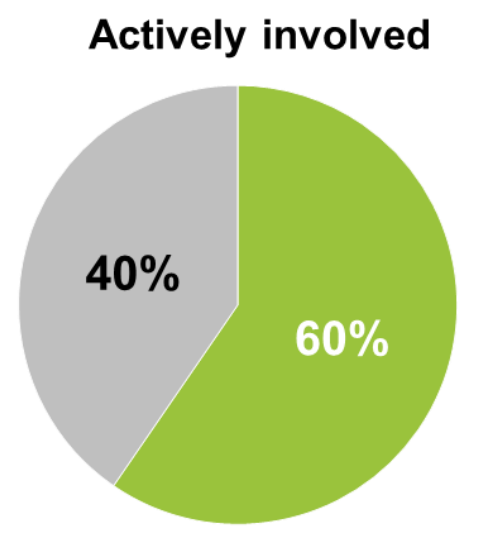

Not involved



$\approx$ Male $=$ Female

Base: 20,172

\footnotetext{
${ }^{9}$ Results are based on two-sided tests with significance level 0.05 . Statistical testing is important because it is only in instances where the difference is statistically significant that there is sufficient evidence to indicate that the observed difference has not occurred due to chance, for example due to the particular sample of young people who took part in the CDF at this stage.
} 
Figure 4.2: Disability by involvement

Actively involved

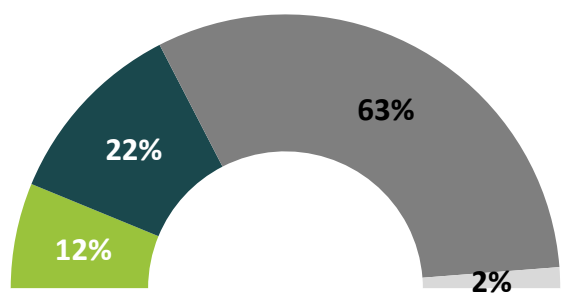

\section{Not involved}

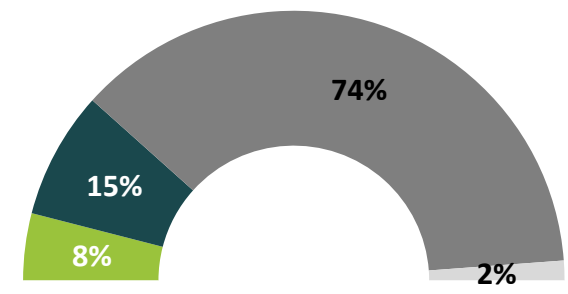

Prefer not to say

Base: 20,141

Those involved were more likely to be aged 21 or over and not have a child(ren). A slightly larger proportion of those involved were from a non-White background compared to those who were not involved. These differences were statistically significant.

Figure 4.3: Age by involvement

Actively involved

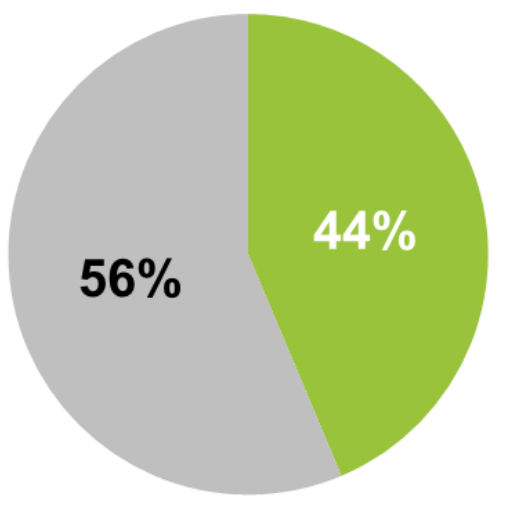

Under $21 \quad 21+$
Not involved

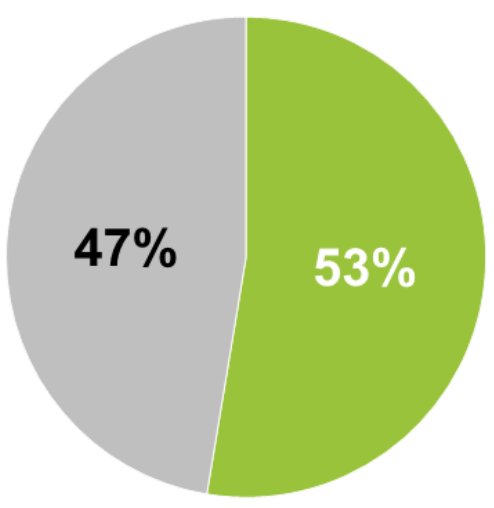

Base: 20,204 
Figure 4.4: Proportion of beneficiaries who have one or more child by involvement

\section{Actively involved}

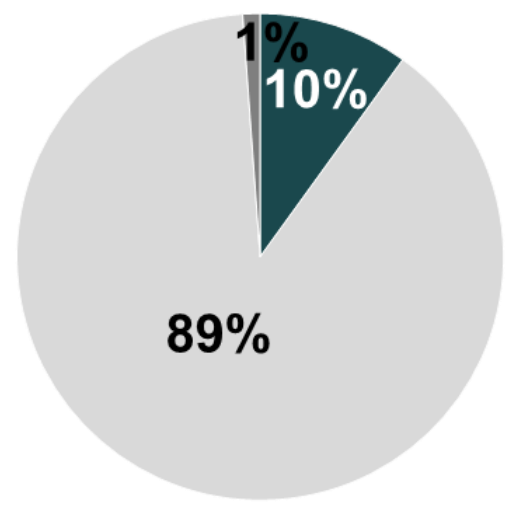

\section{Not involved}

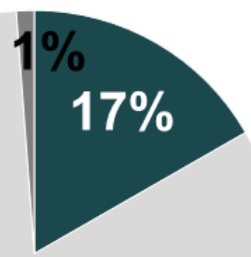

$82 \%$

- Yes $\quad$ No $\square$ Prefer not to say

Base: 19,078

Figure 4.5: Ethnicity by involvement

Actively involved

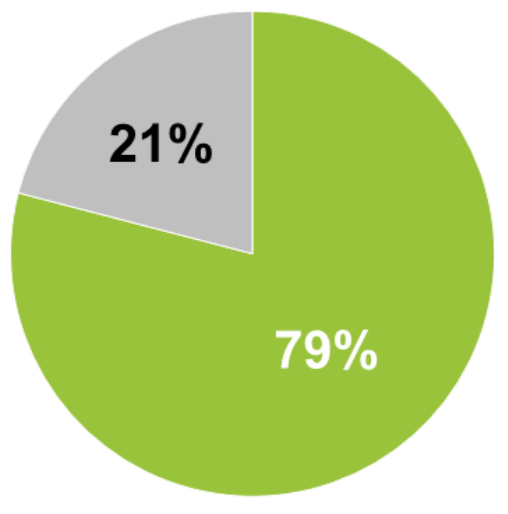

Not involved

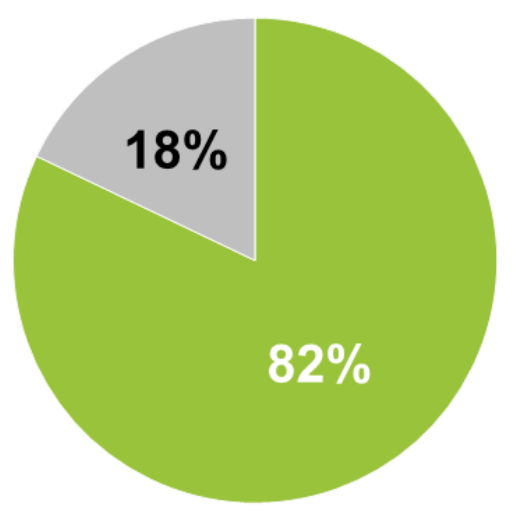

White English/Welsh/Scottish/Northern Irish/British/Irish

$\square$ All other ethnic groups/prefer not to say

Base: 20,215

A larger proportion of those involved indicated they had a religion compared to those who were not involved. The proportion of involved young people who indicated they were heterosexual was smaller than those who were not involved. These differences were statistically significant. 
Figure 4.6: Proportion of beneficiaries who have a religion by involvement

Actively involved

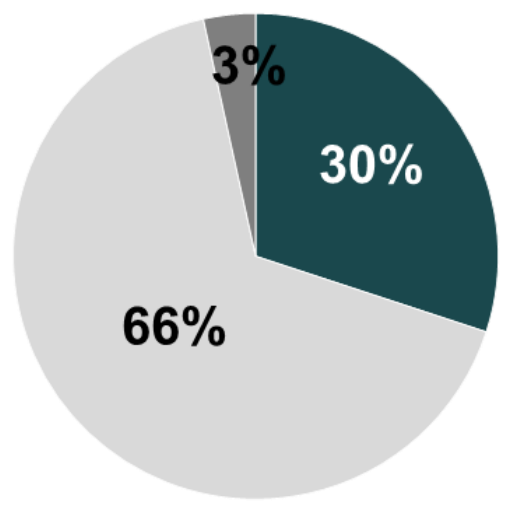

Not involved

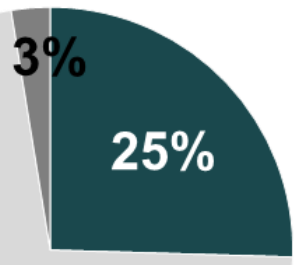

$72 \%$

- Religion $\quad$ No religion $\quad$ Prefer not to say

Base: 20,216

Figure 4.7: Sexuality by involvement

Actively involved

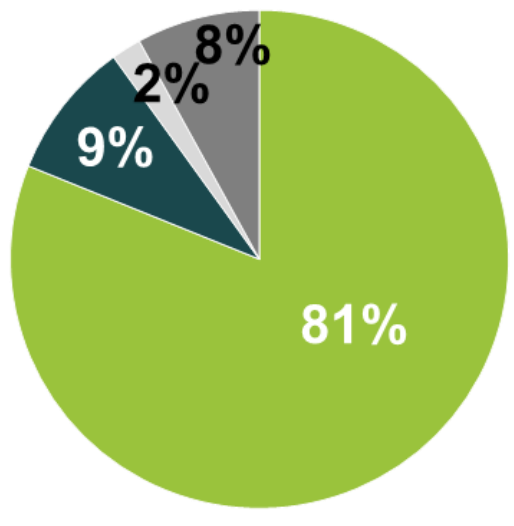

Not involved

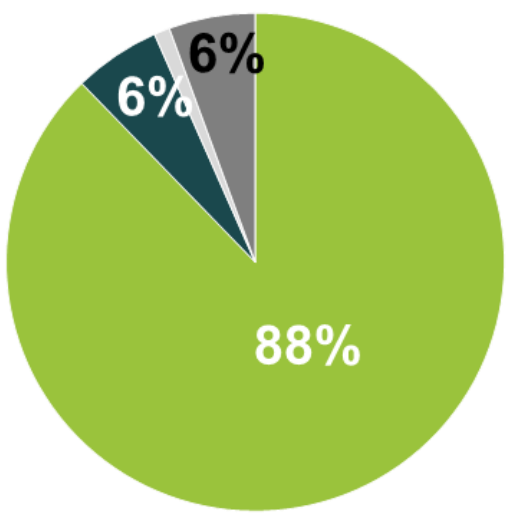

- Heterosexual (straight) - Other sexuality

Don't know

- Prefer not to say

Base: 20,213

\section{Other baseline characteristics}

Young people involved in Talent match are more likely to have 5 GCSEs $A^{*}$-C, compared to those not involved, and more likely to have completed an apprenticeship or formal education before joining Talent Match, or to have undertaken a work placement or volunteering (although less likely to been in paid employment). 
Figure 4.8 below provides a brief overview of the other baseline characteristics of those actively involved and those not as involved.

Young people involved in the programme were more likely to have achieved 5 GCSEs $A^{*}-C$ and not have experienced one or more of the prior life experiences of: local authority care, a criminal conviction, alcohol or drug dependency, mental illhealth or homelessness. These differences were statistically significant.

The proportion receiving benefits was almost the same for each of the two groups and the difference was not identified as statistically significant. There was little difference in the proportion living with their parents/guardian and this too was not identified as a significant difference.

Figure 4.8: Other baseline characteristics by involvement


Base: 18,069 - 20,189

\section{Labour market experience at baseline}

The labour market experience of the two groups at baseline is detailed below in Figure 4.9. The greatest difference identified between those involved and those who were not involved, was in who had completed an apprenticeship or a formal education course before starting on the programme. The proportion that had done this was 10 percentage points higher for those involved in the programme compared to those who were not. Those involved were also more likely to have undertaken some form of work experience or volunteering before starting on the programme. In 
contrast those not actively involved were more likely to have applied for jobs or have gained employment before joining Talent Match. These differences discussed were statistically significant.

The Common Data Framework does not identify the reasons for these differences. However, the different characteristics of young people who have and have not been involved are likely to be important. Young people who have been involved have high level qualifications and have experience in unpaid work situations but may well be facing significant challenges to labour market participation, including ill-health and disability and potentially also discrimination on the grounds of sexuality. This raises important questions around the scope for involvement in Talent Match to address some of these challenges, a point which is returned to in the final section of this report.

Figure 4.9: Labour market experience at baseline by involvement

Actively involved
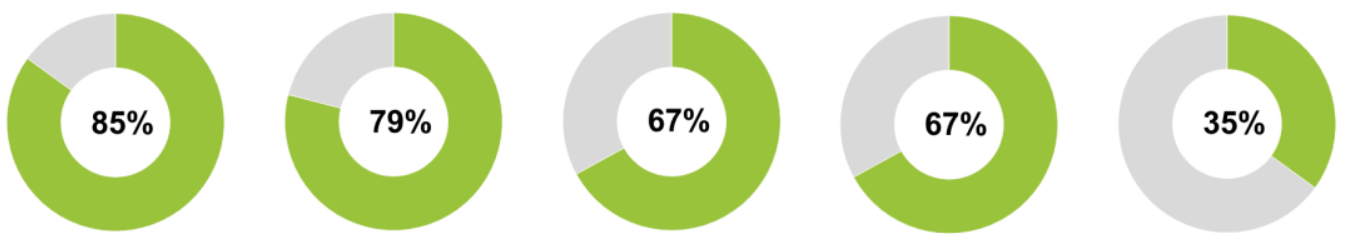

Not involved

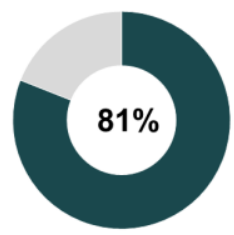

Undertaken some form of work

experience or volunteering

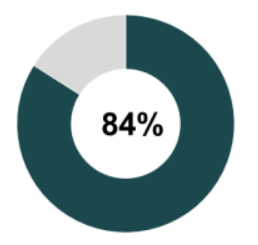

Applied for jobs

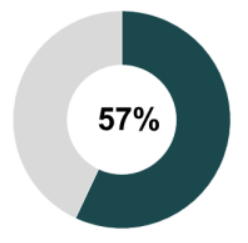

Completed an apprenticeship / completed a formal education course

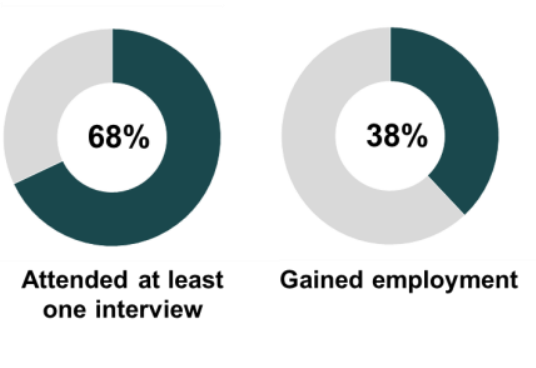

Base: 20,148

\subsection{Support received from Talent Match partnerships}

This section details the support young people have received from Talent Match partnerships by whether they were actively involved or not.

Figure 4.10 below shows how the types of support received from Talent Match differs between those involved and those not involved. For every type of support, the proportion in receipt was larger for those actively involved, and for each type, excluding 'other', the differences identified were statistically significant. This might be anticipated, given the close engagement with a range of Talent Match activities, and the need for Talent Match partnerships to provide young people with support for involvement. The greatest differences were in support with travel, peer mentoring, basic skills and support in addressing practical barriers. In addition, the proportion receiving counselling was double for those who had been actively involved compared to those who had not. 
Figure 4.10: Type of support received by involvement

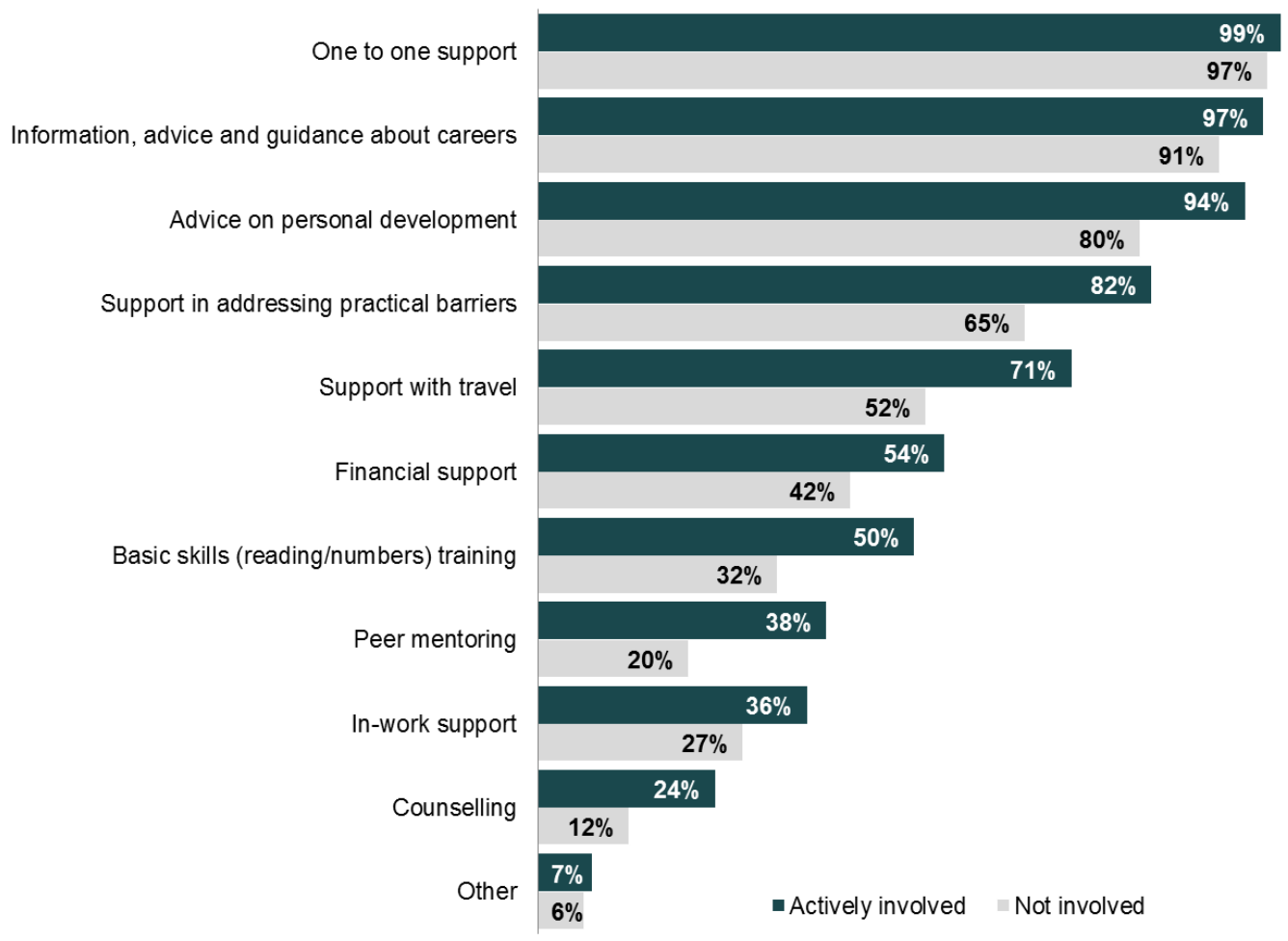

Base: 15,177

Those who were involved were also more likely to have received larger packages of support compared to those who were not as involved. Over half of those involved had received seven or more forms of support, compared to just 30 per cent of those who had not been involved (see Figure 4.11 below). This difference was statistically significant.

Figure 4.11: Number of forms of support received by involvement

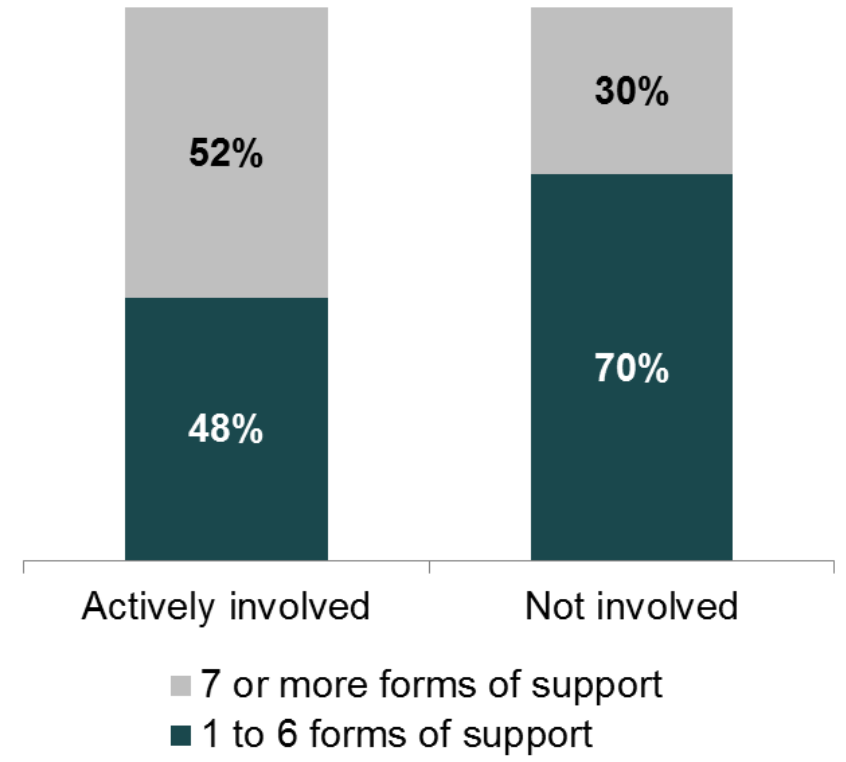


In summary, this section has looked at the characteristics of those involved in Talent Match, their previous labour market experiences and whether they have received more or less support compared to young people who were not involved. The majority of young people who have been involved are male, and aged over 21 years. Compared to those who have not been more involved in the programme they are older, more likely to have a limiting or non-limiting disability, better qualified, more likely to be non-heterosexual, have completed an apprenticeship or formal education before joining the programme, or to have undertaken a work placement or volunteering and they have received more support from Talent Match partnerships. They are less likely to have children, to have experienced negative prior life experiences or to have been in paid employment. All of these differences are statistically significant.

The next section looks at the impact of involvement on young people and Talent Match partnerships, through analysis which explores relationships between involvement and individual outcomes, case studies of involvement and analysis of Talent Match partnership data on the ways in which young people's involvement has contributed to programme delivery. 


\section{The impact of involvement}

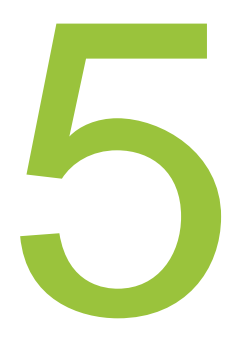

\subsection{Introduction}

This section explores the impact of involving young people in Talent Match in three ways:

- Using Common Data Framework data to identify the types of outcomes achieved by young who have been involved in Talent Match. A key focus of this analysis is examining whether young people involved in Talent Match have achieved different outcomes, compared to those who were not as involved.

- Outlining case studies of involvement to highlight young people's experiences of involvement and how they feel it has benefited them.

- Looking at the impact of involvement on Talent Match partnerships, using partnership survey data and data from partnership visits and thematic studies.

\subsection{Young People's Outcomes}

This section examines whether young people more involved in Talent Match have achieved different outcomes compared to those who were not involved. The outcomes explored range from 'hard' outcomes, such as securing and sustaining employment, through to 'soft' outcomes associated with well-being.

The impact of type of involvement on outcomes is also examined. For the purposes of analysis, the types of involvement explored earlier on have been grouped into clusters as follows:

\section{1. Project management:}

- $\quad$ membership of the Core partnership group or committee;

- $\quad$ management of the Talent Match Partnership and/or service delivery;

- commissioning of services.

2. Evaluation and communications:

- evaluation, research and gathering feedback;

- marketing;

- media and dissemination.

3. Frontline delivery:

- engaging other young people/Outreach;

- delivering services. 
The analysis presented here is based on follow up Common Data Framework returns from six months onwards.

A descriptive assessment of the relationships between involvement overall and outcomes or not is presented, ${ }^{10}$ followed by analysis using logistic regression modelling to assess the relative importance of involvement in explaining outcomes achieved. ${ }^{11}$

\section{Primary hard outcomes}

This section compares the primary 'hard' outcomes achieved by young people involved in Talent Match and those who were not and explores differences by type of involvement.

Young people involved in Talent Match are slightly less likely to have secured employment compared to those who have not been involved. However, there is no significant association between involvement and employment outcomes, and no significant difference in the percentages of involved and non-involved young people achieving sustained employment.

\section{Securing employment}

Securing employment is defined as those who have indicated they are working 16 hours per week or more or are self-employed. Young people who state they are working less than 16 hours per week due to commitments ${ }^{12}$ which limit the number of hours they can work are also counted on this measure. A slightly smaller proportion of those actively involved had secured employment compared to those not actively involved in the programme (see Figure 5.1 below) and this difference was statistically significant at 0.05 level. Again, this may be a reflection of the challenges faced by this group in securing employment.

Figure 5.1: Proportion securing employment by involvement

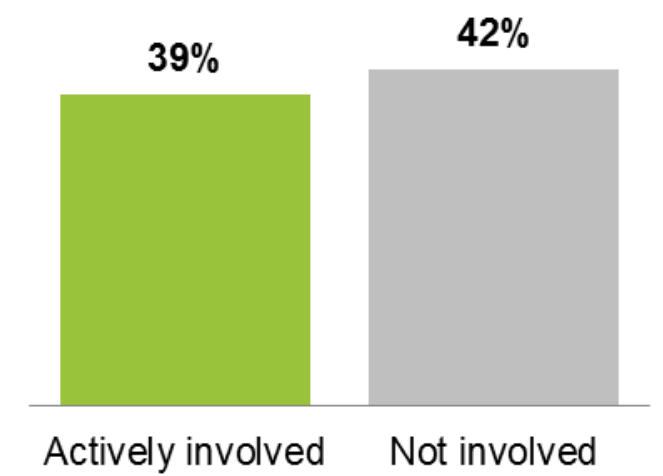

Base: 12,206

\footnotetext{
${ }_{11}^{10}$ A z-test for proportions has once again been used to test for statistical differences.

${ }^{11}$ Enter method was utilised - this method adds explanatory variables to the model in a single step.

${ }^{12}$ Caring responsibilities / childcare commitments / disability / ill health or education commitments which limit the number of hours they can work.
} 
Figure 5.2 below shows how the proportions of Talent Match participants securing employment differ according to type of involvement. A greater proportion of those who had been involved in either project management or frontline delivery had secured employment compared to those involved in evaluation and communications. It is important to note however that a substantial number of young people were actively involved in more than one way. Twenty-three percent had been involved in each of the three types of involvement and 26 per cent had been involved in two of the methods. Therefore it is difficult to decipher from the analysis presented in Figure 5.2 below exactly which type of involvement has had the most impact on outcomes. The logistic regression analysis which follows has attempted to unpick the importance of type of involvement on securing employment.

Figure 5.2: Proportion securing employment by type of involvement ${ }^{13}$

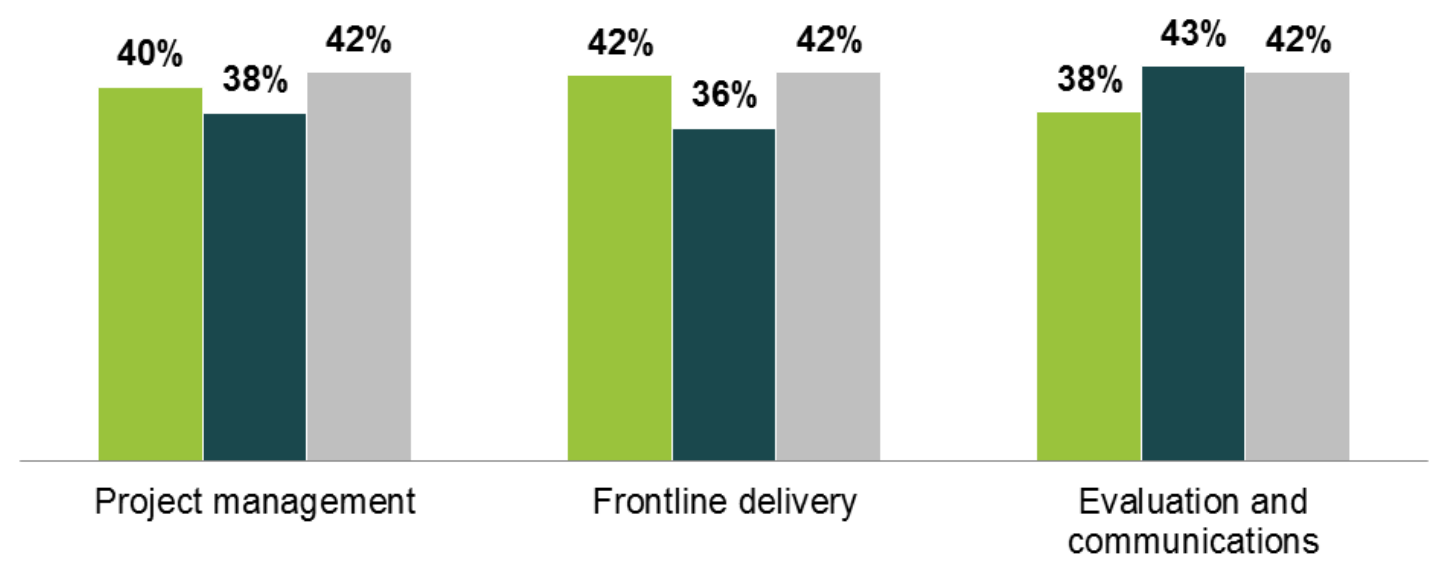

$\square$ Actively involved this way $\quad$ Actively involved but not this way $\quad$ Not involved

Base: 12,206

The relative importance of being involved in Talent Match and securing employment was tested using logistic regression modelling. The analysis examined whether involvement was associated with securing employment over and above the following demographic variables: age (under 21 or $21+$ ), disability status (limiting disability, non-limiting disability and no disability reported), having children (one or more child or no children) and sexuality (heterosexual or other sexuality). These variables were chosen as the ones where the most notable differences were identified between those involved in the programme and those who were not (see Figures 4.1 to 4.7). In addition which Talent Match partnership a young person had worked with was included in the model to account for different labour market contexts. A 'proximity to the labour market' measure, previously created by the evaluation team to quantify the extent to which young people have been supported to move closer to employment, was also included to account for a young person's distance from the labour market at the baseline stage.

The analysis found no statistically significant association between active involvement in Talent Match and securing employment after controlling for all other variables in the model.

\footnotetext{
${ }^{13}$ The difference in the proportion actively involved but not in frontline delivery and not involved at all was statistically significant. The difference in the proportion involved in evaluation and communications and not involved at all was also statistically significant.
} 


\section{Tanya}

Tanya left school with at least 5 GCSEs grades $A^{*}-C$ and went on to complete a twoyear Level 3 course in public services. After completion she began a Level 3 catering course which she dropped out of after 1 year due to personal issues. When Tanya joined Talent Match she was in receipt of Income Support and Carers Allowance due to her formal caring responsibilities to her grandmother. At this time Tanya wasn't looking for work and she was unsure about her goals and career direction; she expressed an interest in catering and hospitality or animal care. Her main barrier to work was low confidence:

I've always had no self-confidence, none, I could send my CV, do all that but it were seeing somebody and talking about it in the interview just really scared me.

Tanya had already gained some work experience when doing the catering course, working in the college restaurant one night every week. In addition to this, she helped out at a family friend's business during their busy times. Three months after joining Talent Match Tanya secured a part-time Catering Assistant job, and, although her neighbour had told her about this vacancy, Tanya acknowledged that her Talent Match Coach had played a key role in building her confidence and preparing her for the interview:

I wouldn't have been able to do that interview without her at all... she helped me with my CV and cover letter and interview techniques.

The Talent Match Coach invited Tanya to take part in the Youth Board and other youth activities and events, but Tanya lacked the confidence to get involved. This also prevented her from getting to know other young people on the programme; she went to Talent Match offices for one-to-one support and left immediately after her appointment without engaging with any wider programme activities - Tanya reported, "I might cross someone who was waiting outside, but I never spoke to them".

The contact with her Talent Match Coach "dropped off" as soon as Tanya got into work. She acknowledged her role in distancing herself from Talent Match as soon as she got into work, "I just forgot all about it really and just wanted to get on with what I were doing".

At six months Tanya was working at least 30 hours per week in the same role, and was no longer in receipt of Jobseekers Allowance. Two years on (in 2018), Tanya is a chef having completed her NVQ Food Production course at level 2. This position brings more responsibilities and greater remuneration.

Tanya recognised her grandparents as providing a constant source of support which motivated and encouraged her - "too much support from my grandma and grandad". Even when she had doubts they provided encouragement:

"yeah come on, you know you can do it...you get your foot in here and then you can get somewhere else...they've just always supported me and pushed me along and say the right things...you know you can do that and you know you can do better than that. It does help".

Her grandparents have played a fundamental role in driving Tanya to fulfil her potential. Throughout her childhood and schooling Tanya was encouraged to finish everything that she started, "I couldn't quit it until I'd got rosettes...my grandma would set me a target...I was never allowed to quit until I'd got something out of it... That's always in the back of my mind." Having started life in an unstable family, the security and support provided by her grandparents since they became her formal guardians has allowed her to achieve her goals. 
Another model was run to examine the role of each of the three types of involvement and their association with securing employment. Each type of involvement was compared to not being involved this way, either through involvement in a different method or not being involved at all. The same demographic variables were also included in the analysis along with Talent Match partnership and the proximity to the labour market measure at baseline. This analysis found no statistically significant association between being involved in each of the three types of involvement compared to not being involved each way and securing employment.

\section{Sustained employment}

Sustained employment is defined as securing employment for at least six months if an employee and 12 months if self-employed. There was minimal difference in the proportions of those actively involved in the programme securing sustained employment compared to those who were not (see Figure 5.3 below). Around one fifth of each group had secured sustained employment and the small difference between them was not statistically significant.

Figure 5.3: Proportion securing sustained employment by involvement

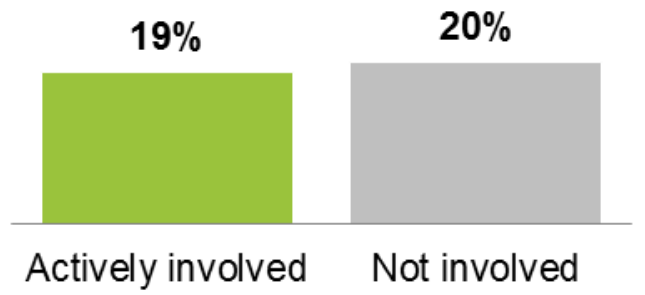

Base: 12,206

Figure 5.4 below shows how the proportions of Talent Match participants securing sustained employment differ according to type of involvement. There was minimal difference across the three types of involvement. For each type the proportion achieving this outcome was lower for those actively involved but not in this way. That the proportion was smaller for all three types can be explained again by the large number of young people actively involved in more than one way. Therefore to help unpick the importance of type of involvement on securing this outcome logistic regression has been used once more and is discussed below. 
Figure 5.4: Proportion securing sustained employment by type of involvement $^{14}$

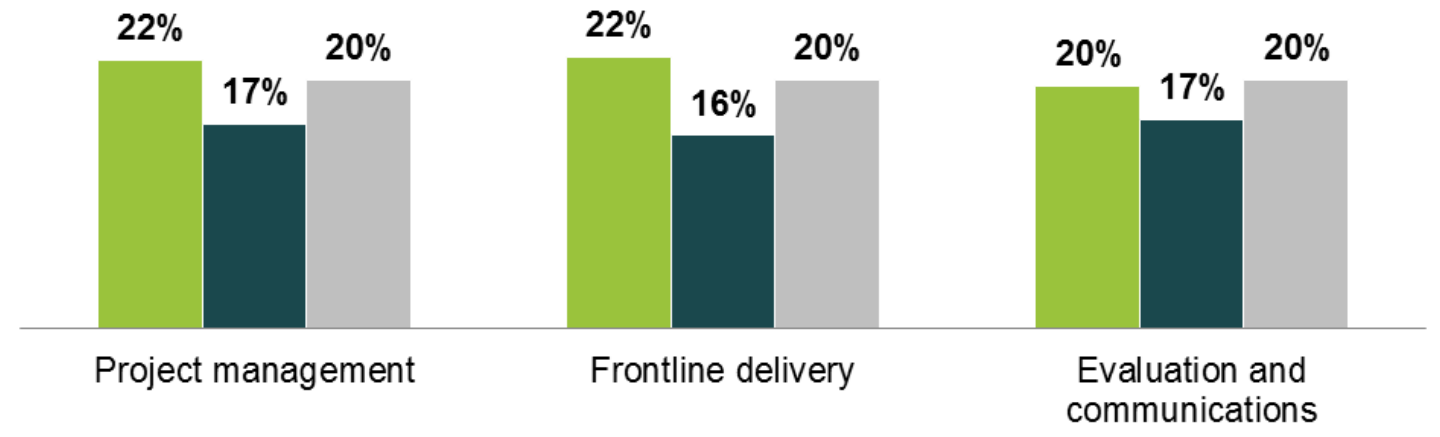

$\square$ Actively involved this way $\quad$ Actively involved but not this way $\square$ Not involved

Base: 12,206

The relative importance of being actively involved or not and securing sustained employment was tested using logistic regression modelling. The same demographic variables used in the models above were used, along with Talent Match partnership and the proximity to the labour market measure. The analysis examined whether involvement was associated with securing sustained employment over and above these variables.

The analysis found no statistically significant association between involvement and securing sustained employment after controlling for all other variables in the model.

A second model was run examining the importance of each type of involvement and their association with securing sustained employment. Each involvement type was compared to not being involved this way, either through involvement in a different way or not being involved at all. The same demographic variables were included along with Talent Match partnership and the proximity to the labour market measure at baseline. This analysis found no statistically significant association between being involved in each of the three types of involvement and securing sustained employment compared to not being involved each way.

\section{Secondary hard outcomes}

This section examines the secondary 'hard' outcomes achieved by young people. Young people have been defined as achieving a secondary 'hard' outcome if they have either started or completed an apprenticeship or entered formal education and therefore appear likely to no longer be NEET for a considerable period of time.

Young people involved in Talent Match are more likely to have secured apprenticeships or entered education when compared to those who have not been involved.

\footnotetext{
${ }^{14}$ The difference in the proportion actively involved but not in frontline delivery and not involved at all was statistically significant, as was the difference between the proportion actively involved in frontline delivery and actively involved but not in frontline delivery.
} 
As Figure 5.5 below shows, a greater proportion of young people who had been involved in Talent Match had achieved these outcomes compared to those who had not been involved and this difference was statistically significant.

Figure 5.5: Proportion securing apprenticeships/formal education by involvement

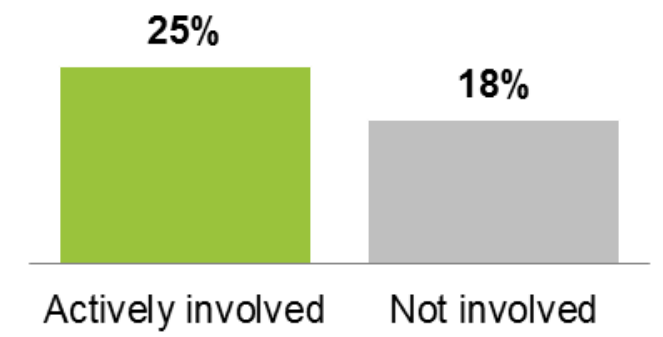

Base: 12,206

Figure 5.6 below shows how the proportions of Talent Match participants securing hard outcomes differ according to type of involvement. The proportions actively involved in frontline delivery or evaluation and communications achieving these outcomes were slightly higher than for those involved in project management. Again logistic regression has been used to further examine the importance of type of involvement on outcomes; bearing in mind young people could be engaged in more than one way.

Figure 5.6: Proportion securing apprenticeships/formal education by type of involvement ${ }^{15}$



$\backsim$ Actively involved this way $\quad$ Actively involved but not this way $\square$ Not involved

Base: 12,206

\footnotetext{
${ }^{15}$ The difference in the proportion actively involved in project management and not involved at all was statistically significant as was the difference between the proportions actively involved but not in project management and not involved at all. The difference in the proportion actively involved in frontline delivery and not involved at all was statistically significant as was the difference between the proportions actively involved in frontline delivery and actively involved but not in frontline delivery. The difference in the proportion actively involved in evaluation and communications and not involved at all was statistically significant as was the difference between the proportions actively involved in evaluation and communications and actively involved but not in evaluation and communications.
} 
The relative importance of being actively involved or not and securing hard outcomes was tested using logistic regression modelling. The demographic variables used in the previous models in this section were used, along with Talent Match partnership and the proximity to the labour market measure. The analysis examined whether active involvement was associated with securing hard outcomes over and above these variables.

The analysis found a statistically significant association between being actively involved in the programme and securing the hard outcomes of either starting or entering an apprenticeship or entering formal education. On average young people actively involved were 1.5 times more likely to have secured these hard outcomes than those who had not been involved when controlling for all other variables.

Another model was run examining the importance of each type of involvement and their association with securing hard outcomes. Involvement in each type was compared to not being involved this way, either through involvement in a different way or not being involved at all. The same demographic variables were included along with Talent Match partnership and the proximity to the labour market measure at baseline.

This second model found a statistically significant association between being involved in frontline delivery and securing hard outcomes and being involved in evaluation and communications and securing hard outcomes. On average young people involved in frontline delivery were 1.5 times more likely to have secured hard outcomes compared to those not involved this way when controlling for all other variables. Young people involved in evaluation and communications were also on average 1.5 times more likely to have secured hard outcomes compared to those not involved this way.

\section{Intermediate outcomes}

Involved young people are more likely to have entered a work placement or taken up volunteering, compared to those who have not been involved.

This section looks at the intermediate outcomes achieved by young people. Young people have been defined as achieving an intermediate outcome if they have either entered a work placement or taken up volunteering and have therefore taken a step towards the 'hard' outcomes above ${ }^{16}$. A noticeably greater proportion of those actively involved in the programme had secured these outcomes compared to those not involved (see Figure 5.7 below) and this difference was statistically significant. This may be due in part to young people's involvement itself being considered as volunteering or work experience by partnerships.

\footnotetext{
${ }^{16}$ Note that this figure may include some Talent Match participants who also went on to gain other outcomes, including employment.
} 
Figure 5.7: Proportion securing work placement/volunteering by involvement

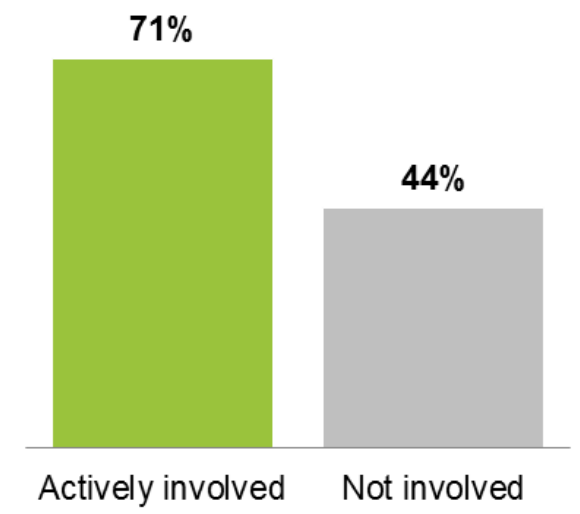

Base: 12,206

Figure 5.8 below shows how the proportions of Talent Match participants securing intermediate outcomes differ according to type of involvement. A slightly greater proportion actively involved in project management or frontline delivery had achieved these outcomes compared to those involved in project management. Again logistic regression has been used to further examine these differences by type and is discussed below. 
Figure 5.8: Proportion securing work placement/volunteering by type of involvement $^{17}$

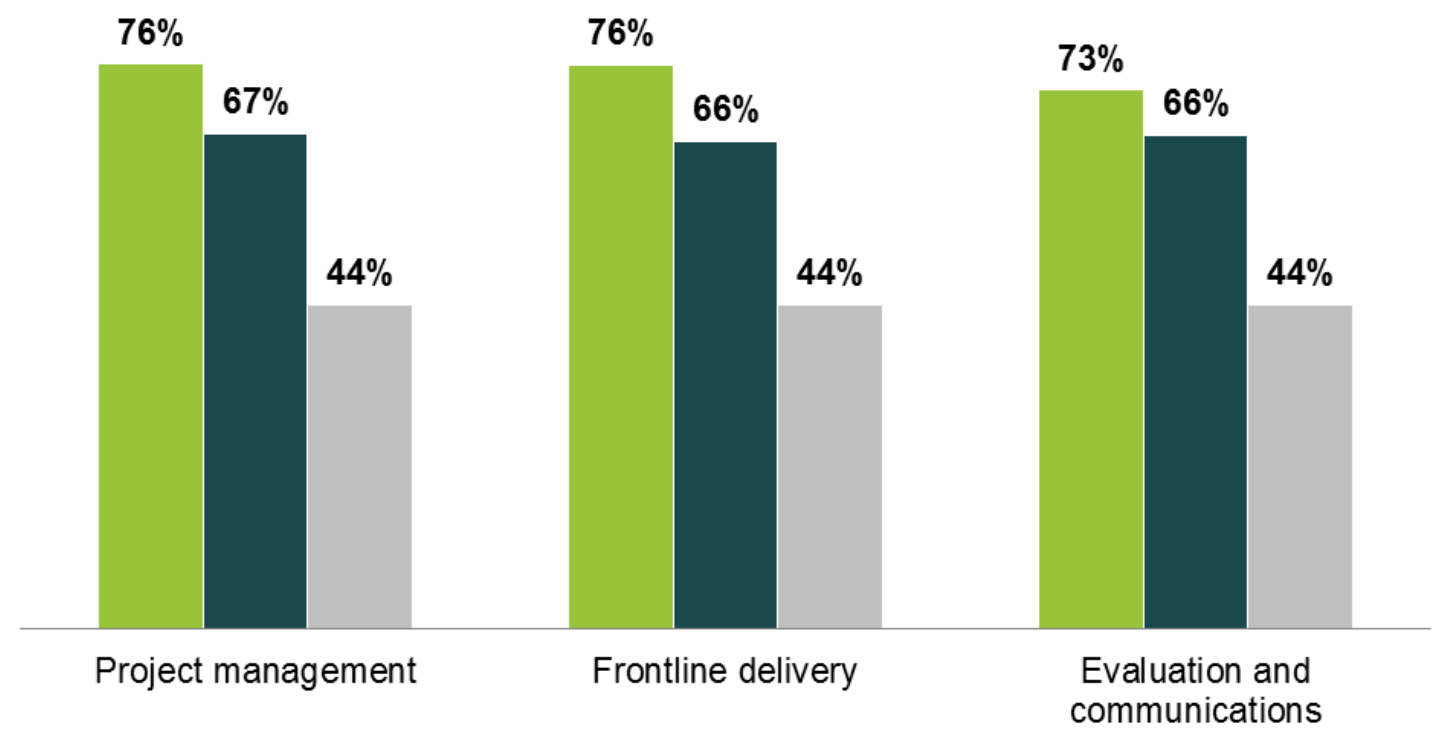

- Actively involved this way $\quad$ Actively involved but not this way $\square$ Not involved

Base: 12,206

The relative importance of being actively involved in the programme or not and securing intermediate outcomes was tested using logistic regression modelling. Again, the demographic variables used in the previous models discussed were used, along with Talent Match partnership and the proximity to the labour market measure. The analysis examined whether active involvement was associated with securing intermediate outcomes over and above these variables.

The analysis found a statistically significant association between being actively involved in the programme and securing the intermediate outcomes of either entering a work placement or taking up volunteering. On average young people actively involved were 2.9 times more likely to have secured these intermediate outcomes than those who had not been involved when controlling for all other variables.

\footnotetext{
${ }^{17}$ The difference in the proportion actively involved in project management and not involved at all was statistically significant as was the difference between the proportions actively involved but not in project management and not involved at all. The difference in the proportions between those actively involved in project management and actively involved but not in project management was also statistically significant. The difference in the proportion actively involved in frontline delivery and not involved at all was statistically significant as was the difference between the proportions actively involved but not in frontline delivery and not involved at all. The difference in the proportions between those actively involved in frontline delivery and actively involved but not in frontline delivery was also statistically significant. The difference in the proportion actively involved in evaluation and communications and not involved at all was statistically significant as was the difference between the proportions actively involved but not in evaluation and communications and not involved at all.
} 


\section{Carla}

When Carla joined Talent Match she had been looking for work for over 4 years. Having Left school with at least 5 GCSEs grades $A^{*}-C$ she went to college to do a two-year Level 4 course in Health and Social Care, but dropped out after the first year, realising the course wasn't suited to her interests.

At baseline, her Common Data Framework survey highlighted that she had good basic skills, but on the My Journey scale Carla identified that she struggled with timekeeping, communication and working with others and required a lot of support in these areas to improve. The survey revealed significant difficulty managing her feelings and very low confidence and this was reiterated by Carla during her interview (in May 2018), "I'm kind of like a shy person...I tend to like get nervous when I go for interviews [job]". She expressed low satisfaction with her life and unhappiness.

The things that prevented Carla from getting jobs included a lack of confidence; uncertainty about which jobs suited her; a lack of interview skills; travel costs; and a lack of prior work experience, she explained: "the lack of work experience has sort of weighed me down looking for work".

Since starting with Talent Match she had received different forms of support, ranging from advice on personal development to support with travel, and counselling. She had attended at least one interview and received one-to-one support, and Information Advice and Guidance about careers.

Carla began to volunteer with a Youth Ministry at her church and recorded gaining several benefits through volunteering: gaining work experience; gaining or improving skills; becoming more employable; making new friends; and increasing her confidence. Carla reported that the experience gained through volunteering was useful because she was also interested in a career in Youth Work, which is closely aligned to her role for Youth Ministry.

Carla had been involved in the Talent Match Youth Board for approximately 6-7 months. When asked what Youth Board involved, she explained, in the main this involved attending meetings to share ideas, find solutions for young people and "think of what to do for the youth of today". Her motivations for getting involved were to improve her "confidence" and "self-esteem", and to step outside her comfort zone. Carla reported that she felt more confident in expressing herself - "always say what you feel and don't hold back, there's no right or wrong answer". She commented further on the ability to express her feelings better - "open up and stuff more than I actually did [before getting involved]" and emphasised that this has positively impacted on her personal life as well.

Being involved in Youth Board has helped her to be more organised in other aspects of her personal life - "If I'm going to other places personally or if I go for a job interview or something, it helps me to get there on time or even a bit earlier".

Although Carla is yet to find suitable employment, she has taken up a paid work placement opportunity for two weeks whilst continuing to look for work. Without involvement in Youth Board she felt she'd still be struggling with low confidence issues, "I'd still be in my shell", and was unlikely to have taken up the work placement. Carla went on to explain, "doing the Youth Board and doing the work experience, it's kind of boosted my confidence". Her future aspirations are to find full-time or part-time paid work. 
A further model was run examining the importance of each type of involvement and their association with securing intermediate outcomes. Involvement in each type was compared to not being involved this way, either through involvement in a different way or not being involved at all. The same demographic variables were included along with Talent Match partnership and the proximity to the labour market measure at baseline.

This second model found a statistically significant association between all three types of involvement and securing intermediate outcomes. On average young people involved in project management were 1.5 times more likely to have secured intermediate outcomes compared to those not involved this way, while those involved in frontline delivery were on average 2.1 times more likely to have secured hard outcomes compared to those not involved this way when controlling for all other variables. In addition those involved in evaluation and communications were on average 1.8 times more likely to have achieved these outcomes compared to those not involved via this method.

\section{Well-being}

The following section explores the overall well-being of Talent Match participants over time. The analysis uses a well-being measure used by Office for National Statistics (ONS). At each stage of data collection, the CDF asks young people 'Overall, how satisfied are you with your life nowadays, where nought is 'not at all satisfied' and 10 is 'completely satisfied'?' In terms of analysis, a score of nought to four is considered a 'low score', indicating a low level of personal well-being.

There is no association between involvement and improvements in wellbeing outcomes. However, involved young people are more likely to report improvements across all aspects of the My Journey Scale: confidence, setting and achieving goals, communication, managing feelings, working with others, reliability.

Figure 5.9 below shows that the proportion of young people who initially recorded a 'low score' at the baseline stage and then went on to record a higher score at a later stage (the baseline score is compared to the latest score available) was slightly higher for those who had been actively involved ${ }^{18}$ but this difference was not statistically significant.

${ }^{18}$ This analysis focuses only on those reporting a 'low' score at baseline. Those reporting a higher score at baseline have been excluded. 
Figure 5.9: Satisfaction with life no longer a 'low score' by involvement

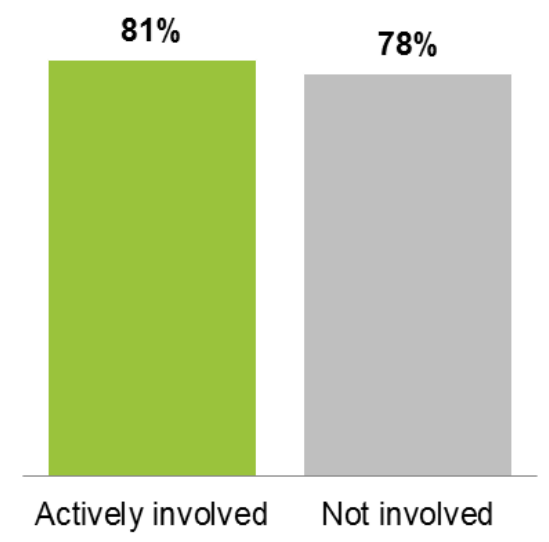

Base: 12,206

Figure 5.10 below shows how the proportions of Talent Match participants recording improvements in well-being scores differ according to type of involvement. A slightly larger proportion of those involved in project management or evaluation and communications had achieved these outcomes compared to those involved in frontline delivery. For both frontline delivery and evaluation and communications the proportion of young people reporting increases in wellbeing was higher for those actively involved but not in these ways. Logistic regression analysis to help decipher the influence of type of involvement has been undertaken and is detailed below.

Figure 5.10: Satisfaction with life no longer a 'Iow score' by type of involvement

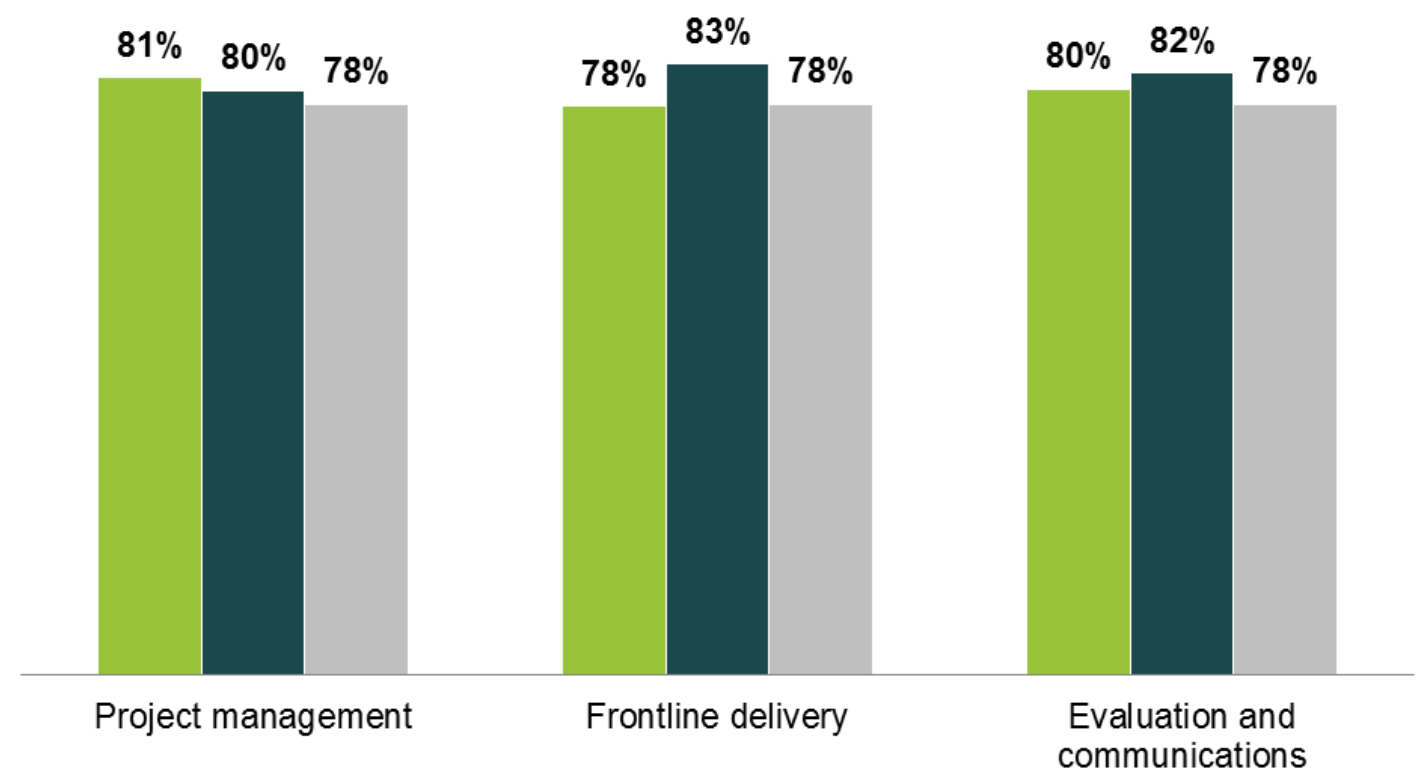

actively involved this way $\square$ Actively involved but not this way $\square$ Not involved 
The relative importance of being actively involved or not and achieving improvements in well-being was tested using logistic regression modelling. Again, the demographic variables used in the previous models were used, along with Talent Match partnership and the proximity to the labour market measure. The analysis examined whether involvement was associated with improvements in well-being over and above these variables.

The analysis found no statistically significant association between active involvement in the programme and improvements in well-being after controlling for all other variables in the model.

Another model was run examining the importance of each type of involvement and association with improvements in well-being. Involvement in each type was compared to not being involved this way, either through involvement in a different way or not being involved at all. The same demographic variables were included along with Talent Match partnership and the proximity to the labour market measure at baseline. This analysis found no statistically significant association between being involved in each of the three types of involvement compared to not being involved each way and improvements in well-being.

\section{My Journey}

At all stages of data collection, beneficiaries are asked to indicate how accomplished they feel they are against a set of skills using the My Journey Scale. The My Journey scale was developed by the Prince's Trust and is shown in Figure A1 in the Appendix to this report.

The final part of this analysis explores improvements in My Journey skills over time ${ }^{19}$. Figure 5.11 below shows that a higher proportion of involved young people scored themselves more available was higher than their score recorded at baseline, was greater for those who had been actively involved in the programme across all six My Journey measures. All these differences were statistically significant.

\footnotetext{
${ }^{19}$ The My Journey scale runs from one to six where: one represents "I find this skill really difficult and I don't care"; six signifies "This skill is a strength of mine and I excel at it." On the following Figures, "low" represents a score of one or two, "medium" a score of three or four and "high" a score of five or six.
} 
Figure 5.11: My Journey Scale - higher score recorded than at baseline by involvement

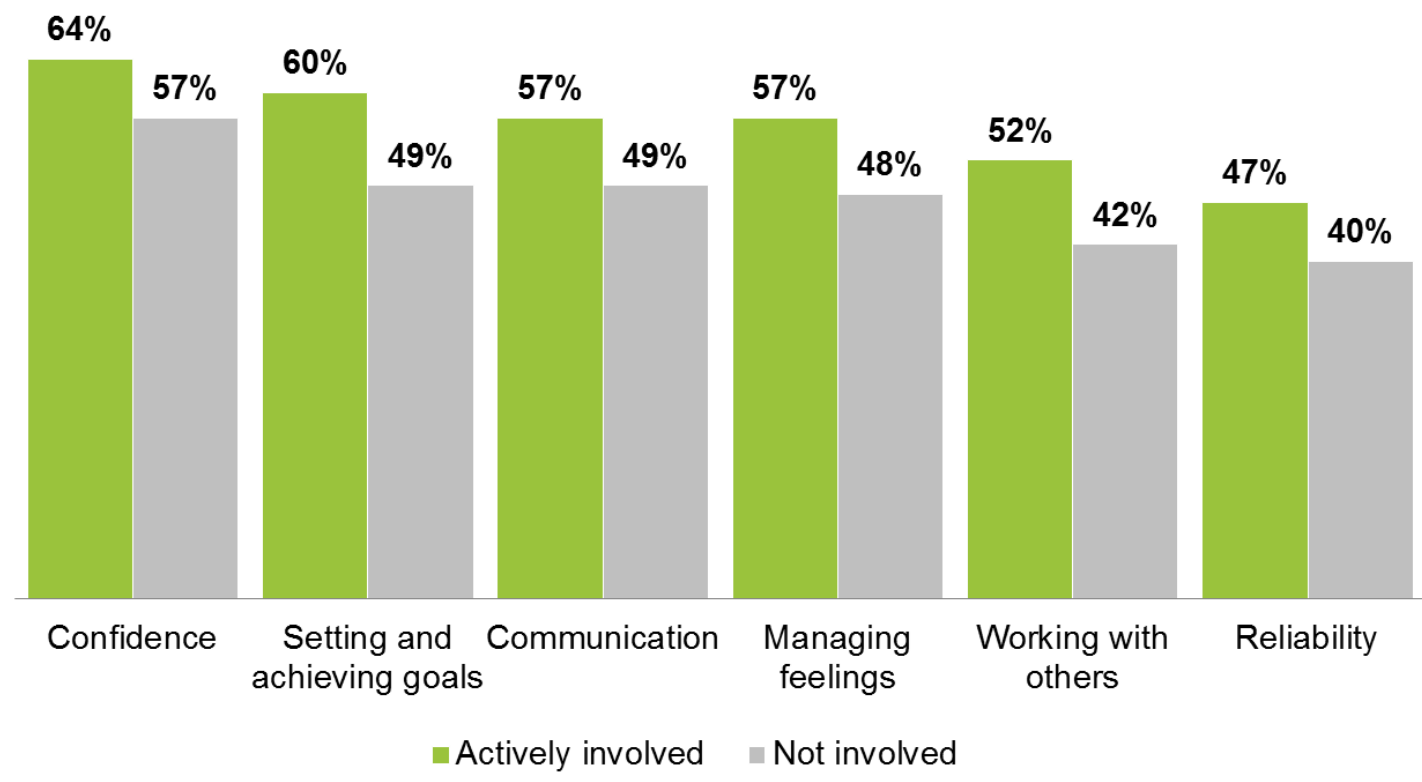

\section{Daniel}

When Daniel first engaged with Talent Match he was struggling with communication, finding it very difficult to work with others, and had problems with his mental health. His three goals with Talent Match were to improve his basic skills, develop good specific skills for the job he wanted to do (graphics), and to undertake some form of work experience.

Daniel became involved the local Talent Match steering group. Being on the steering group opened up opportunities for Daniel to attend events and to travel. He began to meet people and get out and about, and with this, his confidence began to grow. He commented:

I'm not very comfortable around new people at the start and I can be really awkward. As I grew to know these people [in the steering group] I grew a bit more open with the way I talk to people. I needed a way to get to know new people and understand and bring my communication skills back up because at first it was a bit slow cos it was formal and I was a bit intimidated but I was sitting around with people and eventually I got my confidence up and I could talk freely with them which I'm really happy for.

Other opportunities were also taken up, including attending a skills show and sitting on a recruitment panel: "It was a massive confidence boost, I honestly loved it...it's surprisingly enjoyable". Daniel recognised that by meeting people, and participating in activities, such as a residential, and visiting other Talent Match partnerships, he was able to develop his social skills:

That gave me a lot more boost, it means I was in again social situations talking, I was also there with, in a professional mind-set as well, but I was also meeting other people in similar situations to me or working with people with similar situations to me.

Daniel has secured employment through Talent Match and although he is still experiencing mental health issues, he feels that involvement in Talent Match had been an important contributing factor in finding work. He commented

If it wasn't for being in social situations I would have found it really awkward to go and talk to people so that would have affected me being able to go to work. 
Figures $5.12-5.17^{20}$ show how the proportions of Talent Match participants making improvements across the six My Journey measures differ according to type of involvement. For all six measures there were only small differences identified when comparing those actively involved across each of the three ways. For example, both 65 per cent of those actively involved in either project management or evaluation and communications had recorded a higher score than at baseline for 'confidence' and the proportion was only slightly higher for those involved in frontline delivery. Looking at those actively involved in the programme, but not in each of the specified ways, identifies some larger differences. For example, 56 per cent of those involved in the programme but not in evaluation and communications had recorded a higher score for 'setting and achieving goals' compared to 62 per cent of those involved but not in project management. However, overall the differences identified were small. For each of the six measures logistic regression analysis has been undertaken to help further understand the influence of type of involvement and is discussed below.

Figure 5.12: 'Confidence' - higher score recorded than at baseline by type of involvement

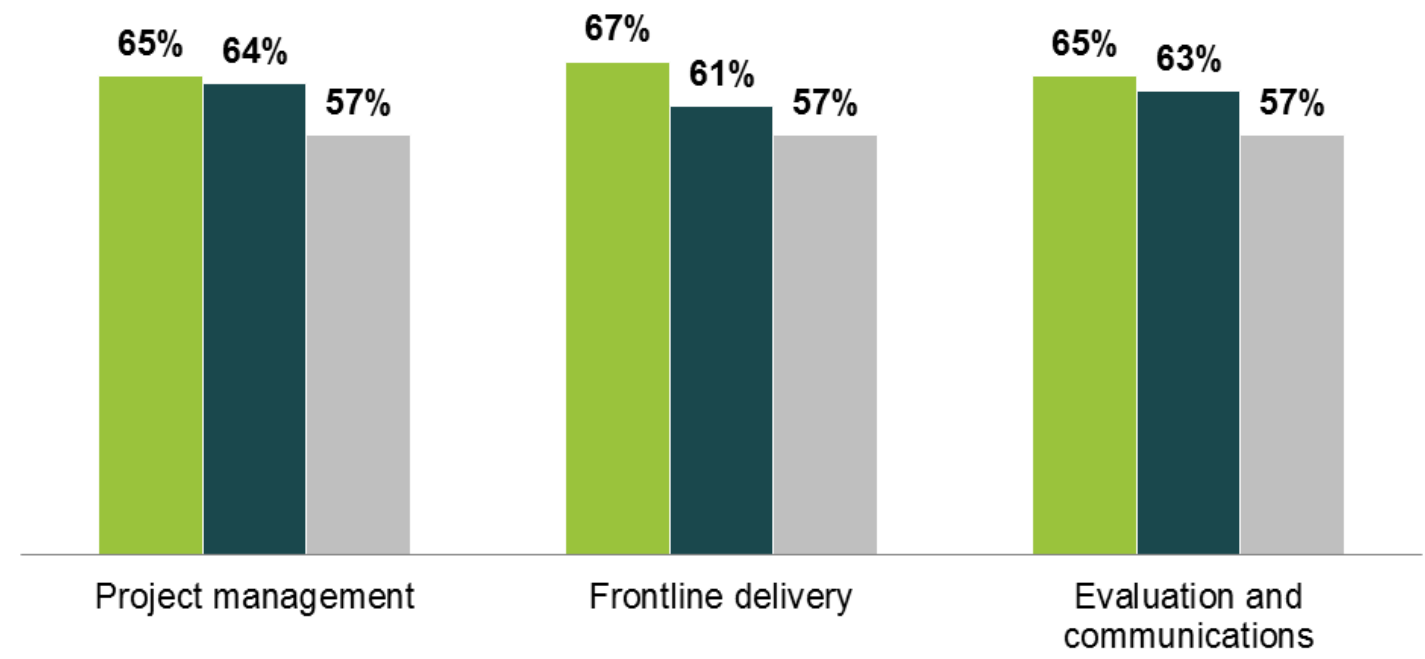

$\square$ Actively involved this way $\quad$ Actively involved but not this way $\quad$ Not involved

Base: 11,985

\footnotetext{
${ }^{20}$ Across all six measures the difference in the proportions actively involved in project management and not involved at all was statistically significant as was the difference between the proportions actively involved but not in project management and not involved at all. Across all six measure the difference in the proportions actively involved in frontline delivery and not involved at all was statistically significant as was the difference between the proportions actively involved but not in frontline delivery and not involved at all excluding 'confidence'. Across all six measure the difference in the proportions actively involved in evaluation and communications and not involved at all was statistically significant as was the difference between the proportions actively involved but not in evaluation and communications and not involved at all for the following three measures: 'working with others', 'managing feelings' and 'reliability'.
} 
Figure 5.13: 'Setting and achieving goals' - higher score recorded than at baseline by type of involvement

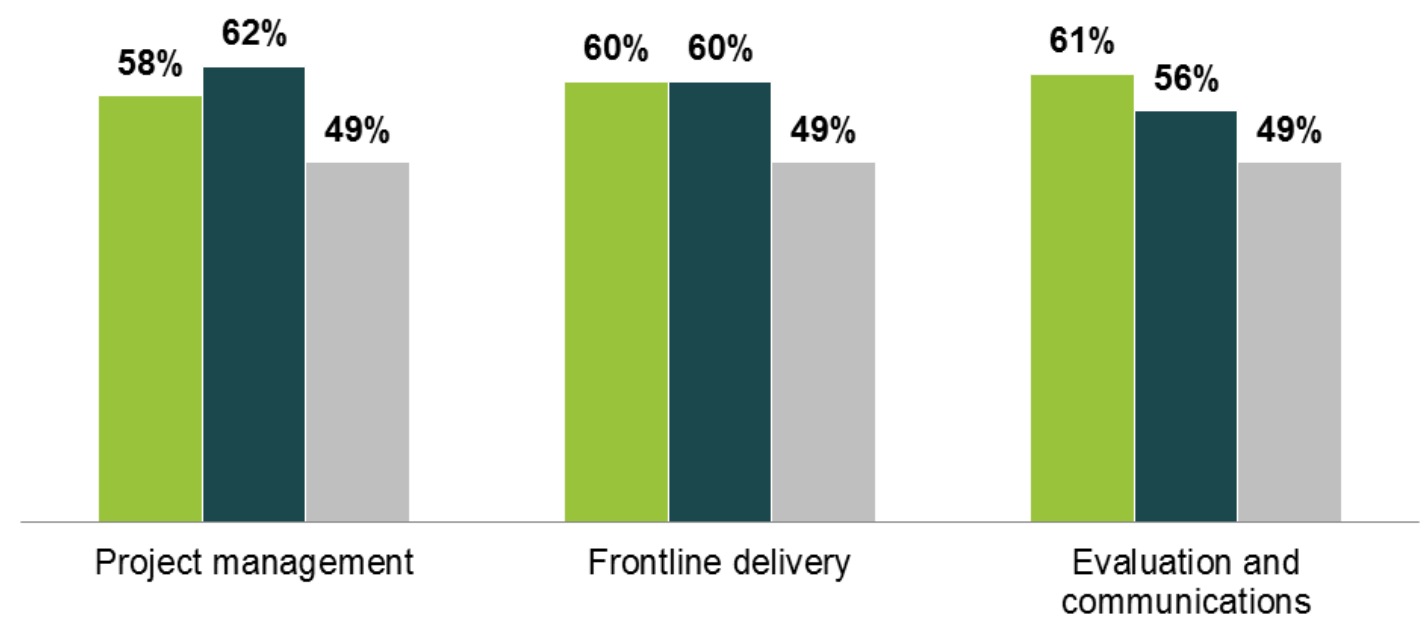

$\square$ Actively involved this way $\quad$ Actively involved but not this way $\square$ Not involved

Base: 11,987

Figure 5.14: 'Communication' - higher score recorded than at baseline by type of involvement

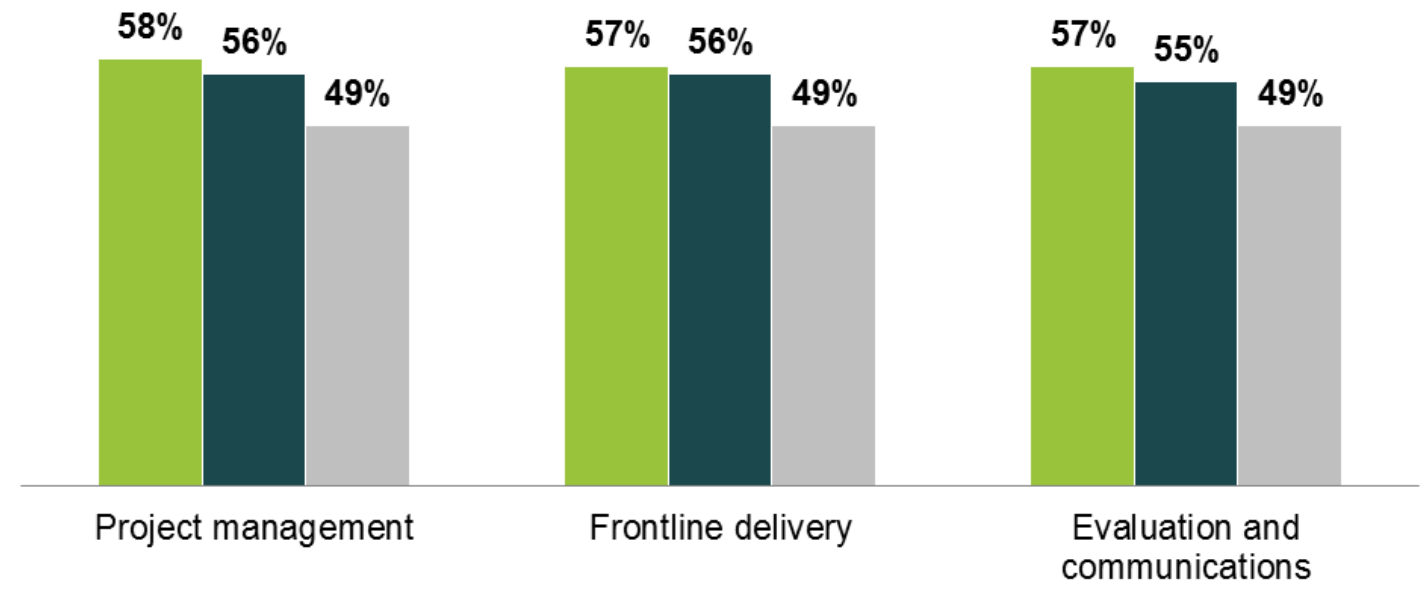

$\square$ Actively involved this way $\quad$ Actively involved but not this way $\square$ Not involved 
Figure 5.15: 'Managing feelings' - higher score recorded than at baseline by type of involvement

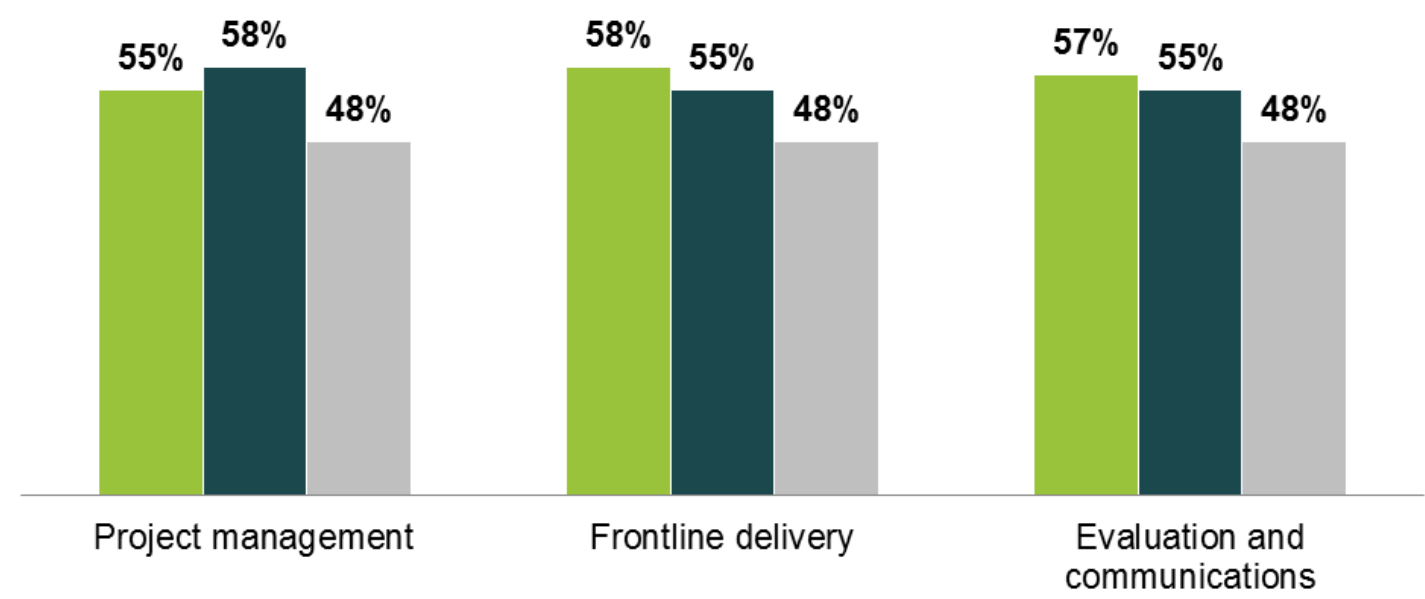

$\square$ Actively involved this way $\quad$ Actively involved but not this way $\square$ Not involved

Base: 11,965

Figure 5.16: 'Working with others' - higher score recorded than at baseline by type of involvement

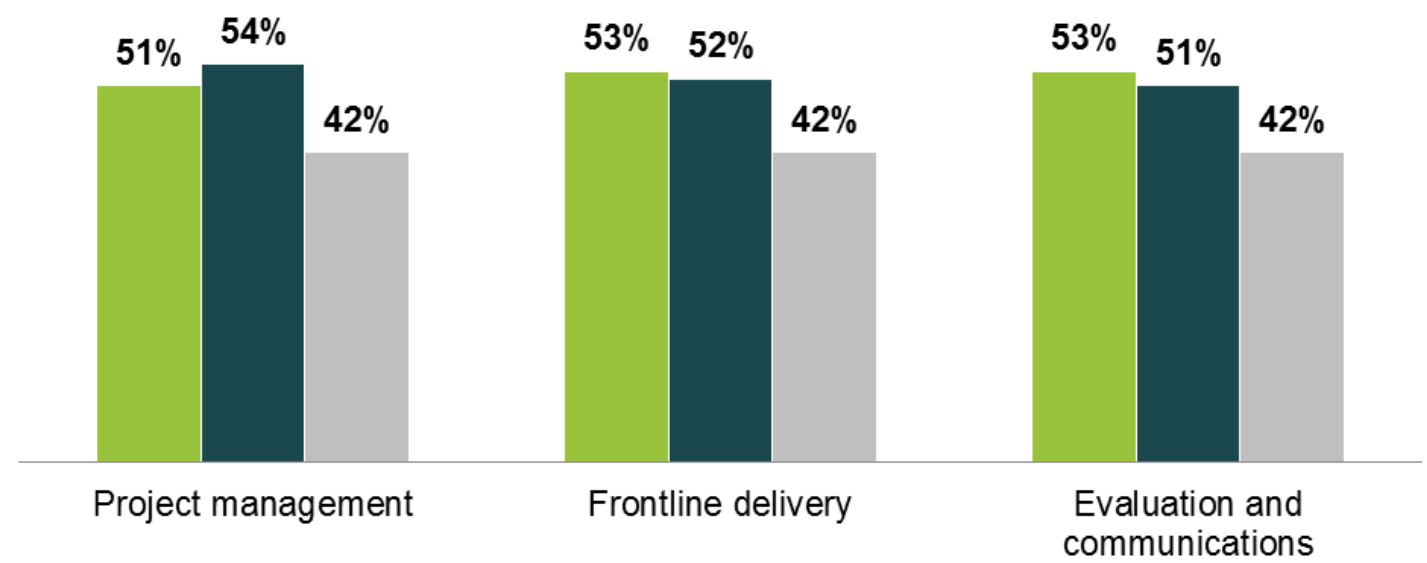

$\llbracket$ Actively involved this way $\quad$ Actively involved but not this way $\square$ Not involved 
Figure 5.17: 'Reliability' - higher score recorded than at baseline by type of involvement

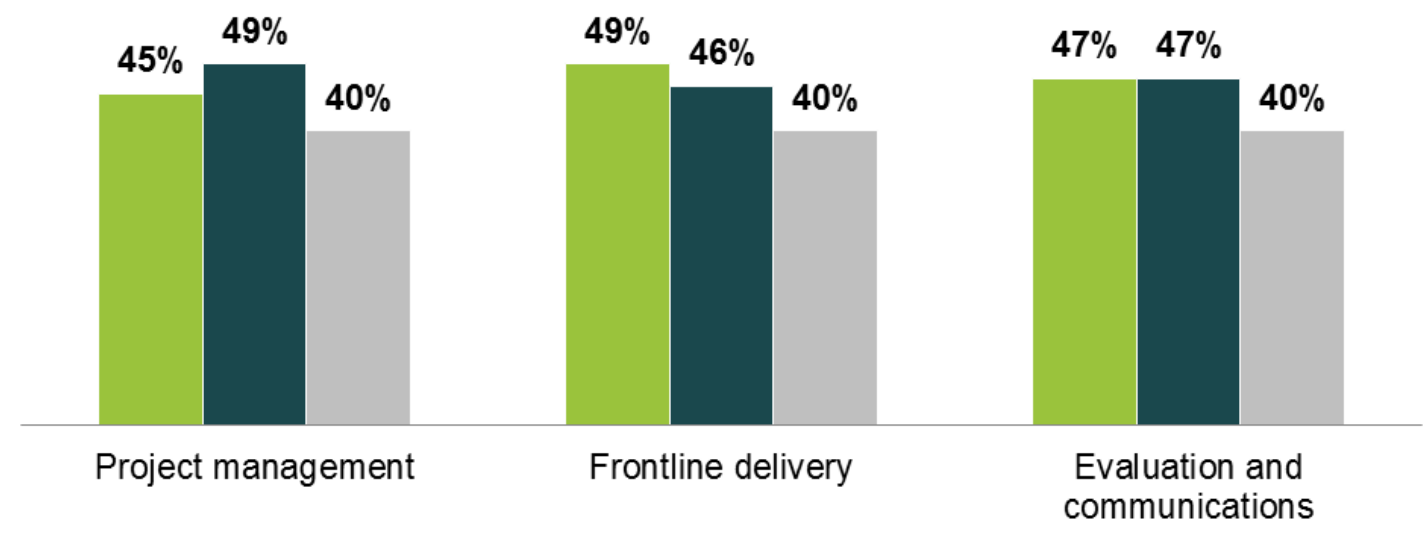

$\backsim$ Actively involved this way $\quad$ Actively involved but not this way $\square$ Not involved

Base: 11,996

The relative importance of being actively involved or not and making improvements across the My Journey scale was tested using logistic regression modelling. Again, the demographic variables used in the previous models were used, along with Talent Match partnership and the proximity to the labour market measure. The analysis examined whether active involvement was associated with improvements on each of the six My Journey measure over and above these variables.

The analysis found statistically significant associations across all six My Journey measures between active involvement in the programme and recording a higher score after controlling for all other variables in the models. For the two measures of 'working with others' and 'setting and achieving goals', on average young people actively involved were 1.3 times more likely to have reported a higher score than at baseline than those who had not been involved when controlling for all other variables. Similarly, on the four measures of 'communication', 'managing feelings', 'confidence' and 'reliability', on average young people actively involved were 1.2 times more likely to have reported a higher score than at baseline than those who had not been involved when controlling for all other variables.

Another series of models were run examining the importance of each type of involvement and their association with improvements on each of the six My Journey measures. Involvement in each type was compared to not being involved this way, either through involvement in a different way or not being involved at all. The same demographic variables were included along with Talent Match partnership and the proximity to the labour market measure at baseline. This analysis found a number of statistically significant associations between being involved in each of the three types of involvement compared to not being involved each way and improvements on the My Journey scale.

On average when controlling for all other variables:

- Young people involved in project management were 1.3 times more likely to have recorded a higher score for 'communication' compared to those not involved this way. 
- Participants involved in evaluation and communications were 1.3 times more likely to have recorded a higher score for 'setting and achieving goals' compared to those not involved this way.

- Young people involved in frontline delivery were 1.4 times more likely to have recorded a higher score for 'confidence'; 1.3 times more likely to have recorded a higher score for 'managing feelings'; and 1.3 times more likely to have recorded a higher score for 'reliability' compared to those not involved this way.

In summary, analysis of individual outcomes for young people suggests that those young people who had been involved were significantly more likely to have taken up an apprenticeship or entered into education, a work placement or volunteering, when compared to those who had not been involved but slightly less likely to have secured an employment outcome. Evidence on the characteristics of involved young people suggests that they may face significant barriers to finding work, and involvement has acted as an important mechanism for moving these young people closer to the labour market.

There is no statistically significant difference in personal well-being outcomes for young people who have and have not been involved, as measured by ONS wellbeing questions. It is important to recognise that for some young people personal well-being is likely to be influenced by issues such as ill-health or disability which are beyond the scope of the Talent Match programme. However, young people who were involved had significantly greater improvements across all six dimensions of the 'My Journey' scale: confidence, setting and achieving goals, communication, managing feelings, working with others, reliability. These outcomes may be a more relevant indication of the impact of Talent Match for involved young people.

Case studies of young people who have and have not been involved in Talent Match confirm that there is no direct association between involvement and outcomes, and that for these young people (as with all Talent Match participants) a range of circumstances and life experiences influence their experience of and outcomes from the programme. The case studies illustrate that those who embed in the Talent Match structures do report an increase in confidence, an improvement in social skills, and a sense of worth. Talent Match acts as a protective scaffold where, for example, family fail to consistent support. In cases where young people have a sense of security and access to support, they fair well even if confidence and sense of worth is low. Encouragement and guidance, whether that is from Talent Match or family, impacts on individuals' outcomes positively. However, some needs are so complex, for example, based on learning difficulties or chaotic lives, that the support has a lesser or short-lived impact.

\section{Emma}

Emma has lived at home with her parents all her life. She has a number of health issues. Having Left school with the highest level of qualification at Level 1 (e.g. GCSEs $D-G)$ and has been in receipt of Job Seekers Allowance since leaving school.

Emma was involved with local employment provision focused on getting young people, aged between $16 \& 25$ years old, into sustainable paid employment. She secured brief (approximately three months) employment in retail and two work trials with different companies. In both instances, the companies decided not to keep her on after her work trials without providing her any explanation.

Baseline data from the Common Data Framework reveals a high level of labour market engagement: prior to registering with Talent Match Emma had undertaken work experience and volunteering, taken up additional training, applied for jobs, attended at least one interview, and, completed a formal education course. She recorded having 
confidence in herself, an understanding of the skills employers were looking for, she had identified her short and long term goals, and the ability to put together a CV. On the My Journey scale she rated herself highly in terms of communication skills, working with others, setting and achieving goals, and rated herself fairly highly in terms of confidence and reliability. However, Emma identified a lack of basic skills (reading/numbers) and a lack of job specific skills as areas in her personal development requiring attention.

Of most importance to Emma was to undertake some form of work experience, apply for jobs, and, to attend interviews. Jobs in animal care and retail were of particular interest to her.

At three months with Talent Match she had received one-to-one support with job search and CV writing. She commented, "I did have a CV beforehand but it wasn't that great". Information, Advice and Guidance about careers was also received from Talent Match. She had undertaken volunteering and reported achieving a number of benefits from her experience, including, skills development, making new friends; and increased confidence.

Even at six months on the Talent Match programme she continued to receive one-toone support and rated this as very good. She was volunteering more and she believed that as a result of the volunteering she had become more employable.

At twelve months she indicated that she had good basic skills (reading/numbers) for the first time since completing her returns. She rated the support received from Talent Match as very good and expressed an interest in cleaning jobs in addition to animal care and retail. Of note, she was no longer volunteering. The progress she had recorded in relation to her basic skills at twelve months had slipped slightly at eighteen months. Emma's level of satisfaction with life and happiness also dropped.

In her most recent in-depth qualitative interview Emma explained that one-to-one support was provided by Talent Match for at least a year and half. The Talent Match Coach was helpful, providing support with job search and interview preparation. Emma only once got involved with other Talent Match activities. This was when she went on a bowling trip with them. When asked why she didn't get involved in further activities or structures such as youth panels/ board, Emma explained that she wasn't asked to be involved in further opportunities. If she had been asked, she might have continued to attend. At the time of the bowling trip, Emma knew someone who worked for Talent Match, but when she left, so did Emma. She explained, "sometimes it's easy [to be involved] when you know someone whose going to be there". In this case, familiarity and knowing other people encouraged involvement, without which, involvement ceased. It seems that Emma's involvement in Talent Match activities was at an early stage and she hadn't got to know other young people to become embedded in the Talent Match youth involvement structures.

Her Talent Match Coach also left her job, but, prior to leaving, introduced Emma to the person who would be her new Coach. However, the new Coach left his job very quickly but didn't connect Emma with a new source of support before moving on. Emma commented, "I felt it [the support] went downhill as soon as she [the first Coach] left". Emma began to disengage from the Talent Match programme.

Emma is currently receiving support from the Jobcentre and the YMCA. She has been looking for paid work since leaving school and doesn't know why she is constantly rejected by employers. She believes she has considerable skills required for retail work, which is the sector she would like to work in. In Emma's view, her health conditions do not have any bearing on her ability to secure or sustain employment. She takes medication which helps manage her conditions. Emma doesn't experience any other barriers to work; financial or caring commitments. Her family life is secure with supportive parents to encourage and advise her. Emma's future aspirations are focused solely on finding paid work. 


\subsection{The impact on Talent Match partnerships}

As outlined above, the involvement of young people in the co-design and co-delivery of Talent Match activities has been a defining feature of the programme. Young people have been involved in the development and delivery of Talent Match in a variety of ways since the programme began and data from the 2018 partnerships survey suggest that Talent Match partnerships have continued to see young people's involvement as an overwhelmingly positive thing, as they did in in both 2014 and 2015.

When asked if the involvement of young people in the elements listed on Figure 5.18 had either assisted or constrained the development and delivery of their programme, partnerships overwhelmingly stated that young people's involvement had assisted delivery for every element.

Of particular relevance is the involvement of young people in the management of the Talent Match partnership and/or service delivery, and in membership of the core partnership group or committee. The majority of respondents indicated that the involvement of young people in partnership governance had greatly assisted delivery. None of the partnerships indicated that any of the elements listed had constrained delivery.

Figure 5.18: Types of youth involvement - assisting or constraining delivery

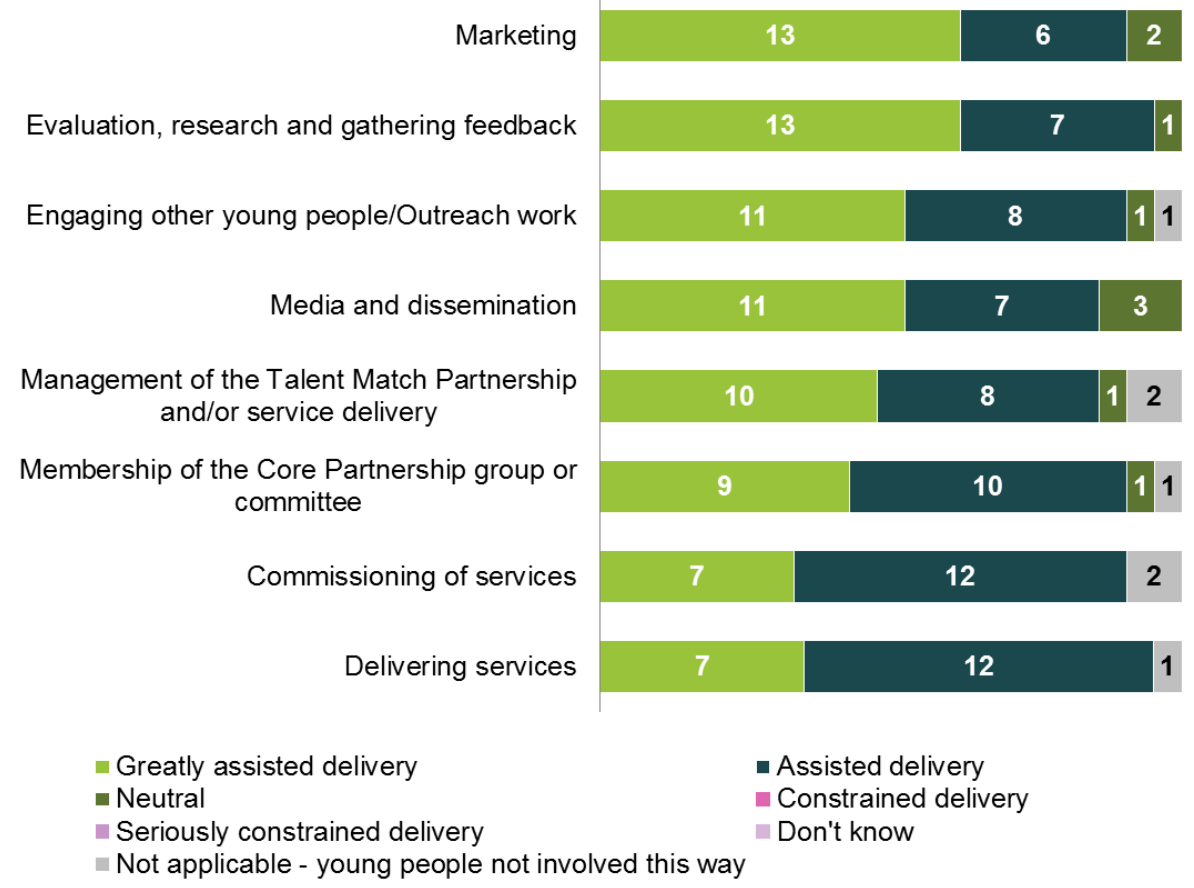

Base: $20-21$

There is clear evidence here that for partnerships, the involvement of young people brings positive benefits. Interviewees spoke to in partnership visits highlighted the important contribution made by young people in bringing a different dynamic to partnerships. The 'lived experience' of young people seeking employment helped shape the nature and delivery of Talent Match activities, and indeed delivery partners (through involvement of young people in interview panels and selection of delivery partners, etc.) 


\section{Talent Match London}

For Talent Match London, one emphasis has been on engaging young people in peer mentoring and active leadership roles. One delivery partner in East London described how Talent Match had "devolved more power to their youth board" by engaging young people proactively in developing employer links and networks. This was described thus: "been fantastic - it's boosted numbers and provision". Social and networking facilities for young people were provided through a 'youth room': a space available every Friday afternoon for young people to meet and play games (pool, table tennis etc.) whilst "meeting like-minded people who are moving forward and not held back by their peers". Employers and service providers also attend to meet young people and provide training and information.

Interviewees highlighted anticipated benefits to involving young people:

- Young people are more likely to remain with Talent Match and, ultimately, commit to any future job if they feel they have been actively involved in designing the programme. Moreover, potential beneficiaries are more likely to sign up if they know that the programme has been designed by young people. One Youth Board member in East London attributed the rise in numbers (from four to 14) to the perception that 'someone was voicing the opinion of young people'.

- More effective outreach activities as young people know best how to do this.

- Better engagement of employers as they know that the programme is youth-led which enhances the commitment of young people.

- Facilitating partnership between delivery organisations: 'It's not about competition all the time' [Youth Board member].

- Encouraging innovation and effective delivery among partners as they are aware they are being evaluated by young people looking to see if activities work. One delivery partner noted, for example, that had restructured their staffing arrangements in response to feedback from young people that they wanted additional support. This led them to move services on separate sites into shared premises so that they could use cost savings to resource additional staff support.

- Freeing up advisers' time to working with beneficiaries where tasks involved in running social or employer engagement events can be handed over to young people.

- Improving the skills and confidence of young people. One Youth Board member described it as a 'great experiences'.

\section{Talent Match Middlesbrough}

In Talent Match Middlesbrough the Young People's Panel grew to around 20 members (from five originally) and became more firmly embedded within the project. The Panel has delivered a range of activities including

- Leading the commissioning process of a new series of activities.

- Creating a promotional video for the project that has been posted on Youtube.

- Inviting a Jobcentre Plus representative to come and answer questions posed by the panel. 
- Developing a newsletter.

- Planning events e.g. 'learn and share' events across the whole partnership and celebration events to recognise the achievements of young people.

- Working on their own theory of change to complement the one developed by project staff.

- Training members to undertake surveys and focus groups in order to collect data that will feed into the local evaluation.

- Creating a welcome pack.

- Engaging in an away day.

Of these activities, the youth-led commissioning process is perhaps the most significant. This saw all project staff, the Core Partnership and the Young People's Panel work together to issue a tender for four different streams of activity: personal and social development; health and well-being; work-related activities; and innovation and creativity. Once bids were in, the process was led entirely by young people who, with the support of the Middlesbrough Volunteer Development Agency, short-listed, interviewed and made final selections over which providers to contract with. This was a step change from previous rounds of commissioning to select delivery partners when young people had worked alongside the Core Group. By contrast, project staff only became involved in this new phase of commissioning to ensure due diligence. This process was almost universally seen to work well although one partner challenged this consensus by suggesting that provision commissioned was not always popular with beneficiaries and highlighted the risks of commissioning being 'too youth led'.

The benefits of youth involvement identified by interviewees included

- Personal development around social skills, CV development and confidence.

- The additional insights they brought to the commissioning process with young people sometimes able to spot potential in organisations bidding to become delivery partners that staff sometimes overlooked: "They look them in the eyes, not just what they are like on paper". Involvement in commissioning was also seen to help young people to gain a sense of responsibility.

- Growing confidence and autonomy among Panel members in running activities themselves: "It's got better and better. We're running the Young People's Panel ourselves rather than relying on the project leads" [Panel member].

- One Panel member described how involvement helped her to "get confidence back" after a period of severe mental health problems that saw her not leave the house for six months. She also identified wider benefits for Panel members of attending the away day: 'It helps to build up trust, we all became closer as a result and developed friendships'. More broadly, the work of the Young People's Panel also serves to advocate for the skills and competencies of young people: "It shows that young people can make a difference and make our voices heard".

- Having an active youth panel encourages beneficiaries to engage and remain with the project as it creates a positive 'community feel' and helps to inspire more 'socially isolated' young people by showing how they can get involved and make decisions. One Panel member also noted that posting the Talent Match video they created on her facebook page helped to spark interest among, and ultimately recruit, some of her friends to the project. 
This section has looked at evidence around the impact of involvement in Talent Match. It has suggested that although there is no clear relationship between involvement and employment or overall well-being outcomes for Talent Match participants, there are individual benefits associated with a greater likelihood of entering into education, an apprenticeship or placement, or taking up volunteering. Those young people who were involved also experienced greater improvements in confidence, setting and achieving goals, communication, managing feelings, working with others, and reliability; suggesting that involvement in the governance and delivery of the programme has provided these participants with an opportunity to develop valuable skills. For partnerships, young people's involvement has been overwhelmingly positive, and has assisted delivery across all elements of the programme. The final section of this report discusses the findings and draws conclusions for the future involvement of young people seeking employment. 


\section{Discussion}

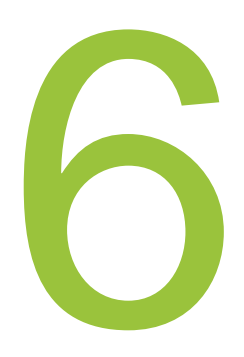

This report has summarised evidence from across the evaluation of Talent Match in relation to the involvement of young people in the governance, design and delivery of Talent Match. A number of themes have emerged:

- Talent Match partnerships have devoted considerable time, resources and energy to the involvement of young people and have seen it, in line with the overall ethos of the programme, as a central aspect of Talent Match provision. There has been a wide variety of processes, structures and funding streams to support involvement across the Talent Match partnerships. There is no clear evidence to emerge from the evaluation around particular approaches or mechanisms that are successful in involving young people, and indeed this has not been the main focus of this report. Perhaps more importantly, what has emerged is a set of principles, or ways of working for young people's involvement which have shaped the overall Talent Match approach. Flexibility to respond to the changing needs and priorities has been paramount, as has ensuring that young people are not discouraged from involvement by limited opportunities for engagement and overly formal processes.

- There have perhaps inevitably been relatively small numbers (compared to the total Talent Match beneficiary population) involved in structures and processes designed to influence the governance and delivery of the programme. This is in line with evidence from other initiatives which confirm that despite the existence of widespread opportunities for engagement only small numbers of programme participants will participate in formal involvement opportunities. Nevertheless, in each Talent Match partnership over 70 young people have shaped local provision, and this is an important difference to mainstream employment support programmes.

- There is evidence that in Talent Match, involvement is associated with some personal characteristics and employment experiences. Notably, those young people who have been involved are more likely to be those with disabilities and who have not experienced prior employment, when compared to their peers who have not been involved. This suggests that involvement in Talent Match has in part acted as an important mechanism for supporting young people who are facing some of the most challenging barriers to labour market participation.

- Perhaps because of this, there is no significant link between involvement and employment, and those who have been involved in Talent Match are not more likely to gain employment outcomes. That is not to say however that there are not substantial individual benefits associated with young people's involvement: those who have been involved have moved closer to the labour market and report greater gains particularly in confidence, communication skills and goal setting. There is also no link overall with improved wellbeing, perhaps again reflecting the fact that many of these young people are experiencing challenges which include ill-health and disability which are beyond the scope of an employability programme. 
- Perhaps the key impacts of young people's involvement are, however, in influencing the work of Talent Match partnerships and other stakeholders. There is ample evidence from the programme that co-production with young people has improved the engagement and participation of young people in the programme (through young people's involvement in outreach and peer support); developed services that are responsive to young people's needs; and influenced the policies and practices of organisations, including employers. These are important outcomes in themselves, and ones which are likely to lead to enhancing the experience of and impact of employment support for all young people.

Lessons from the evidence on young people's involvement in Talent Match include

- Young people's involvement has many forms and changes over time: The ambition to place young people at the centre of Talent Match has been realised by providing a wide range of opportunities for involvement, building in opportunities for social activity and peer support, and learning from experience and revising approaches over time. The ability of Talent Match partnerships to respond flexibly to the views and priorities of young people has been important in encouraging, and sustaining, young people's involvement.

- Young people's involvement improves service quality: Some of the key impacts of young people's involvement are in influencing the work of Talent Match partnerships and other stakeholders, which include employers. This has ensured that the voice of young people has informed the development and delivery of provision across Talent Match areas, and has enhanced the experience of and impact of employment support for all Talent Match beneficiaries. There would be clear benefits to embedding young people's involvement into future provision to ensure that it meets the needs of young people.

- Involvement is an important mechanism for supporting young people who are facing some of the most challenging barriers to labour market participation: The young people involved in Talent Match have included those with disabilities and mental health issues. Opportunities for involvement have enabled these young people to develop skills that they might not otherwise have obtained.

- Involvement helps young people to move closer to the labour market: Those young people who have been involved in Talent Match are more likely to enter formal education, secure an apprenticeship or work placement or take up volunteering than those who have not been involved. These are important steps toward sustained employment, particularly for young people who don't have experience of paid work.

- Involvement supports young people to build skills and confidence: Young people who have been involved in Talent Match report greater gains particularly in confidence, communication skills, goal setting managing feelings, working with others and reliability. In future employability programmes there may be a rationale in seeking to support involvement of those groups for whom these attributes and skills are particularly low.

- Involvement one is part of a range of support that is needed to help young people to progress: The fact that there has been no direct relationship between involvement and improved employment outcomes for young people involved in Talent Match is a reflection of the challenges that this group are facing in finding work. Involvement should be seen as a complement to, but not a replacement for, a range of other activities to support young people to overcome barriers to labour market participation. 


\section{Appendix 1}

\section{wim \\ My Journey Scale}

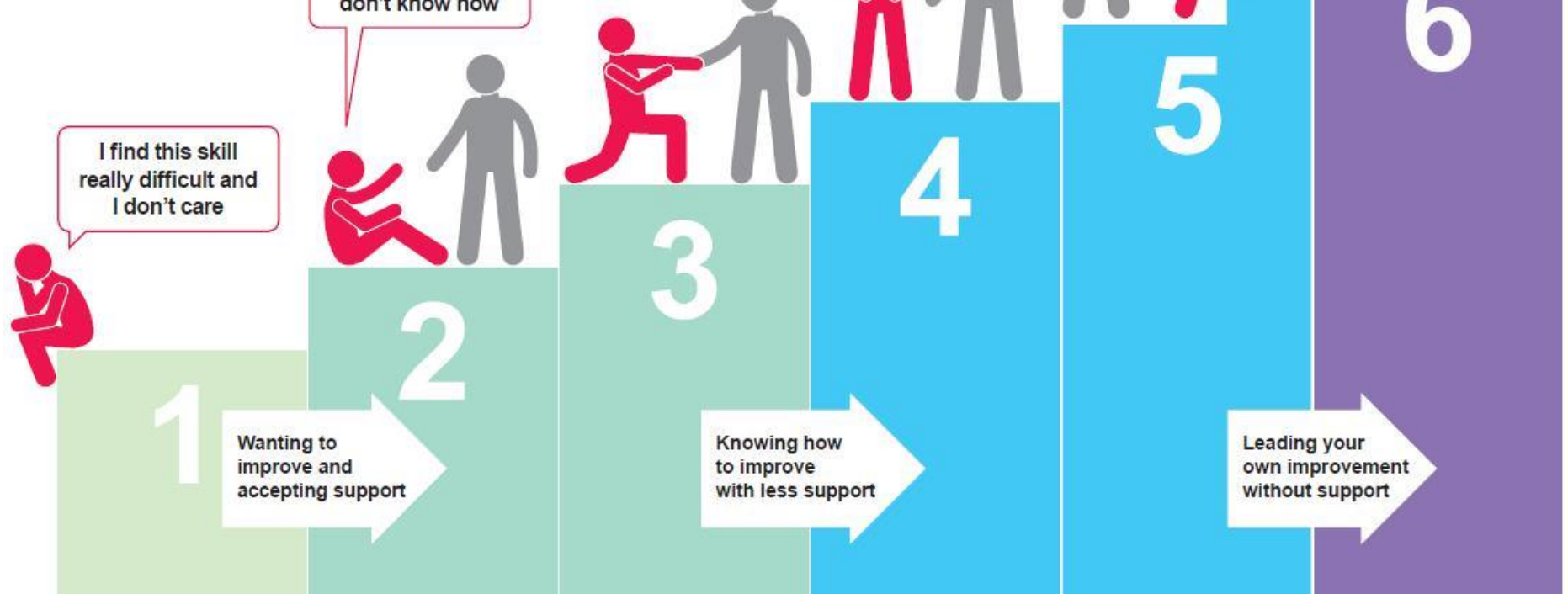




\section{Sheffield Hallam University}

\section{Talent Match Evaluation: Involving Young People}

BASHIR, Nadia <http://orcid.org/0000-0002-1384-4849>, PEARSON, Sarah <http://orcid.org/0000-0001-5049-5396>, SANDERSON, Elizabeth < http://orcid.org/00000003-1423-1670> and WELLS, Peter <http://orcid.org/0000-0002-5200-4279>

Available from the Sheffield Hallam University Research Archive (SHURA) at: http://shura.shu.ac.uk/23174/

\section{Copyright and re-use policy}

Please visit http://shura.shu.ac.uk/23174/ and http://shura.shu.ac.uk/information.html for further details about copyright and re-use permissions. 